Document downloaded from:

http://hdl.handle.net/10251/109805

This paper must be cited as:

Colucci, D.; Fissore, D.; Mulet Pons, A.; Carcel Carrión, JA. (2017). On the investigation into the kinetics of the ultrasound-assisted atmospheric freeze drying of eggplant. Drying Technology. 35(15):1818-1831. doi:10.1080/07373937.2016.1277738

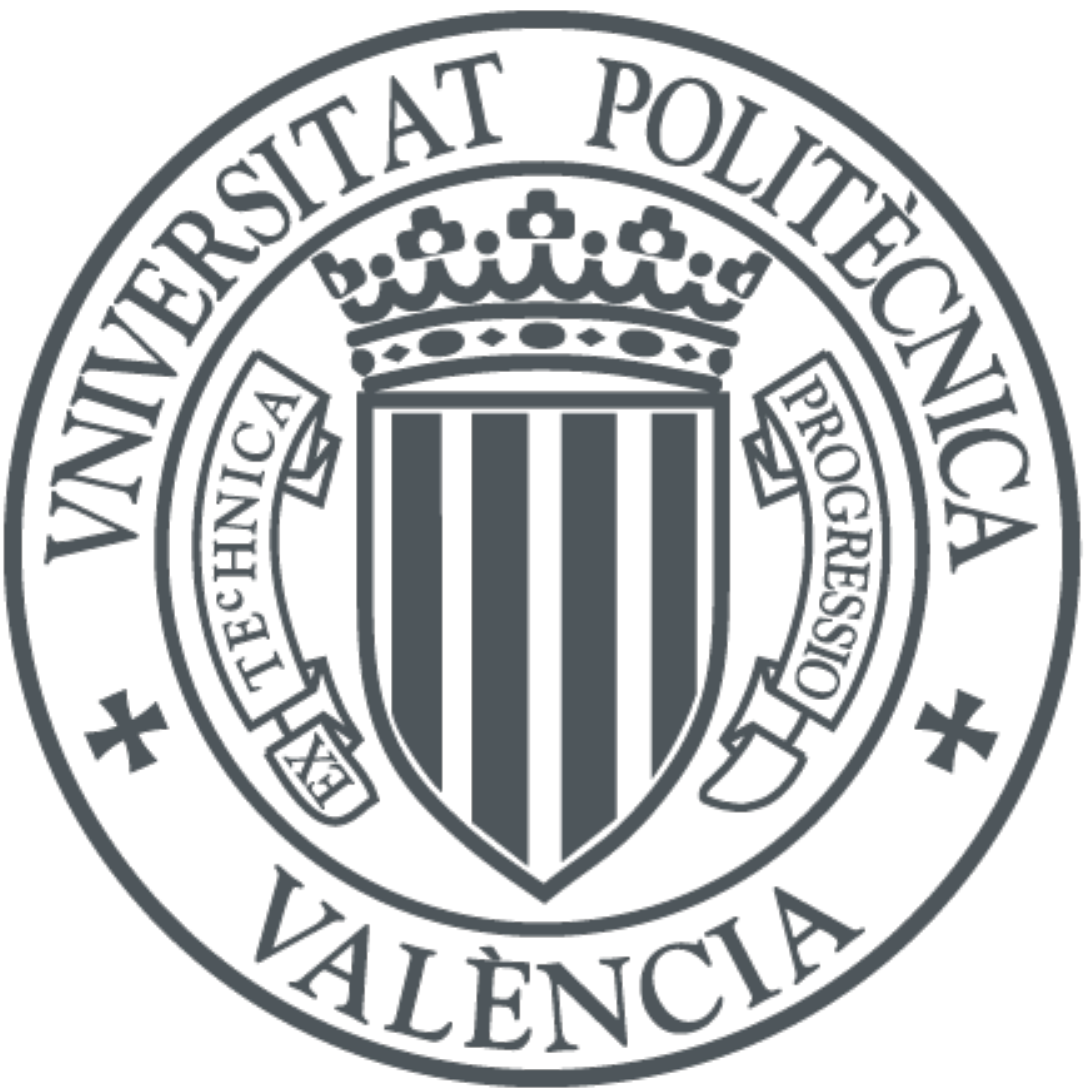

The final publication is available at

https://doi.org/10.1080/07373937.2016.1277738

Copyright Taylor \& Francis

Additional Information 
Submitted for publication in

Drying Technology

\title{
On the investigation into the kinetics of the ultrasound assisted atmospheric freeze drying of eggplant
}

\author{
Domenico COLUCCI ${ }^{1,2}$, Davide FISSORE ${ }^{2}$, Antonio MULET ${ }^{1}$ and Juan A. \\ CÁRCEL ${ }^{1, *}$ \\ ${ }^{1}$ ASPA group. Department of Food Technology. Universitat Politècnica de \\ València. Camino Vera s/n, 46022 València. Spain. \\ ${ }^{2}$ Dipartimento di Scienza Applicata e Tecnologia, Politecnico di Torino, \\ Corso Duca degli Abruzzi 24, 10129 Torino, Italy.
}

\footnotetext{
${ }^{*}$ Corresponding author

Tel.: +34 963879365

E-mail: jcarcel@tal.upv
} 


\begin{abstract}
Atmospheric freeze drying is a highly attractive process for the dehydration of thermosensitive products, like food, due to the fact that water is removed at low temperature by sublimation. Unfortunately, drying times can be very long because of the internal resistance of the product to vapor diffusion: power ultrasound can be an effective means of accelerating the process, thus reducing the operating cost. The aim of this study was to assess the effect of air temperature and velocity, ultrasound power and sample size on the drying kinetics of eggplant (Solanum Melongena L.) samples and, afterwards, to analyze in silico an industrial process. Experiments were carried out under various conditions regarding air temperature ( -5 , $-7.5,-10^{\circ} \mathrm{C}$ ), velocity (2 and $5 \mathrm{~m} \mathrm{~s}^{-1}$ ), power ultrasound $\left(0,10.3,20.5 \mathrm{~kW} \mathrm{~m}^{-3}, 21.9 \mathrm{kHz}\right.$ ) and sample size. Drying rate was measured experimentally. The air velocity showed no relevant effects on the drying kinetics, and the effect of the air temperature was slight when compared to the marked reduction in the drying time obtained when ultrasound was applied. The uniformly retreating interface model was modified to account for the cubic shape of the samples and used to establish the kinetic parameters, in particular to evaluate water diffusivity in the dried product, searching for the best fit between measured and calculated moisture content. The model was finally used to optimize the process in silico, considering an industrial unit as test case. In this case it appeared that power ultrasound can increase the productivity of a tunnel drier up to four or five times, and it allows the operational and fixed costs of the plant to be reduced significantly.
\end{abstract}

\title{
Key words
}

Atmospheric freeze-drying; ultrasound; mathematical modeling; water diffusivity. 


\section{Introduction}

Atmospheric freeze drying (AFD) is the convective drying of a frozen product using a stream of dried and cold air for water removal and heat supply. The main difference with respect to hot air drying is that water is not removed by evaporation, but by sublimation from a completely frozen product. Such a process is feasible as long as a difference in water vapor partial pressure, which is the driving force for water sublimation, is established between the frozen surface of the product and the process air. ${ }^{[1]}$ Since AFD is a low-temperature process, generally carried out at temperatures between $-10{ }^{\circ} \mathrm{C}$ and the initial freezing point of the product, it is a well-known means of achieving better quality in the dried product with respect to hot air drying. ${ }^{[2]}$ Moreover, the process can be carried out continuously, ${ }^{[3]}$ and energy saving of up to $35 \%$ can be obtained ${ }^{[4]}$ compared to vacuum freeze drying. The introduction of a heat pump proved to be an efficient way to further reduce the energy consumption and to control air temperature and humidity. ${ }^{[5,6]}$

The main disadvantage of AFD is that the mass transfer inside the dried layer of the product, from the interface of sublimation to the drying chamber, can become rate controlling, and long process times are required. ${ }^{[7]}$ Either thermal or mechanical energy has to be supplied to the product for the purposes of enhancing the heat and mass transfer phenomena.

An interesting solution for increasing the drying rate could be that of mixing the product with an adsorbent material used for air drying, thus increasing the driving force of the process and taking advantage of the heat provided by water adsorption to enhance ice sublimation. ${ }^{[8]}$ The main problems of this process are the necessity to separate the product from the adsorbent once the drying is completed, the compatibility of the adsorbent with foodstuffs and the non-uniformity of the different particles in the bed that can cause the occurrence of channeling path and blocking effects. ${ }^{[9]}$

Power ultrasound, i.e. acoustic waves with frequencies between 20 and $100 \mathrm{kHz}$ and a power of over $1 \mathrm{~W} \mathrm{~cm}^{-2}{ }^{[10]}$, proved to be an effective, non-toxic and environmentally friendly way to accelerate the AFD process by means of the periodic mechanical stress induced to the system. ${ }^{[11,12]}$ In the last few years, the development of a new type of transducers, able to reach high energy levels in airborne applications ${ }^{[13]}$, led to an increased interest in the application of this technology on an industrial scale. ${ }^{[14]}$

In a solid porous product ultrasound application induces a series of rapid compressions and expansions ${ }^{[15]}$, as happens to a sponge quickly squeezed and released, ${ }^{[16]}$ and this 
mechanical stress helps water vapor to flow out of the dried cake through the natural channels and other micro-pathways created by the ultrasonic wave propagation. ${ }^{[17,18]}$ Another important effect in fluids related to ultrasound application is acoustic streaming. ${ }^{[19]}$ Lighthill $^{[20]}$ gave a mathematical description of this phenomenon, basically due to the dissipation of acoustic energy which generates a momentum gradient and, hence, a fluid turbulent flow. This effect can contribute to enhancing the mass and heat transfer at the solid-fluid interface.

Power ultrasound was applied to the AFD of several fruits and vegetables, namely apple, ${ }^{[5,18,21,22]}$ eggplant, ${ }^{[23]}$ carrot $^{[24]}$ potato, ${ }^{[8]}$ peas, ${ }^{[25]}$ red pepper, ${ }^{[26]}$ zooplankton ${ }^{[27]}$ and fish, e.g. cod. ${ }^{[28,29]}$ Moreover, AFD was demonstrated to be effective even when drying large size samples, resulting in an acceleration of the drying kinetics, with no significant side effects on product quality. ${ }^{[30]}$

The goal of this study was to evaluate the effect of several operating variables, namely air temperature and velocity, ultrasound power and sample size, on the drying kinetics of eggplant (Solanum melongena L.) samples, aiming to set-up a mathematical model of the process for the in silico optimization of the operating conditions and, finally, for the investigation of an industrial-scale AFD unit.

Various types of mathematical models are available for this purpose; they can be divided into two groups: the empirical models and the theoretical models. Many empirical models have been applied to the drying processes, ${ }^{[31]}$ e.g. Bantle et al. ${ }^{[32]}$ studied the AFD process using a modified version of the Weibull distribution. The theoretical models are developed from principles of basic physics. A first group of these models is represented by the diffusion models. In this kind of model, water transport inside the products is supposed to be due to a driving force created by the difference in moisture content. This model assumes the isotropy and homogeneity of the product. ${ }^{[33]}$ However, in a freeze-drying process, the ice sublimates, generating two layers: a frozen inner core and an external porous structure and, therefore, the main hypothesis of the diffusion model fails and the physical consistency of this mathematical approach turns out to be questionable. In any case, this model provides an adequate description of the drying kinetics and has been reported by many authors as a tool with which to quantify the influence of process variables on drying rate. ${ }^{[34,35]}$ A second group of models, able to account for the heterogeneity of the product, is based on the Uniformly Retreating Ice Front (URIF) model proposed by Wolff and Gibert. ${ }^{[4,36,37]}$ In 2015, Warning et al. ${ }^{[38]}$ modified the original URIF model in order to account for the non-homogeneity of ice sublimation.

The purpose of the paper is to analyze the drying process and provide an in silico 
approach to the industrial process optimization. The URIF model was adapted to the cubic shape of the samples used experimentally for the investigation of the process, and it was used to establish the kinetic parameters of the process. Experiments were carried out using eggplant, Solanum Melongena, an interesting vegetable for a drying study due to the high water content, up to ninety-three percent of the whole weight, the great variability of the water content in the product, due to the different varieties, season and method of cultivation (e.g. open field or greenhouse), and the huge amount of seeds, which increases the heterogeneity of the sample. ${ }^{[39]}$

The paper is organized as follows: firstly, details about the experimental approach to the measurement of drying kinetics are given, with the design of experiments used to this purpose. Then, the mathematical model is presented, with the methodology used for the estimation of the kinetic parameters and the investigation of the industrial-scale unit. Finally, the results of both the experimental investigation and the study of the industrial process are presented and discussed, for the purposes of pointing out the pros and cons of power ultrasound application.

\section{Materials and methods}

Fresh eggplants were purchased in a local market (Valencia, Spain) and stored at $4 \pm 1{ }^{\circ} \mathrm{C}$ for no more than two days before being dried. Cubic samples were obtained from the flesh of the vegetable using a household tool. To point out the effect of the sample size, two different cubic sample sizes were considered: cubes with a side of $8.8 \mathrm{~mm}$ and others of $17.6 \mathrm{~mm}$.

The drying experiments were carried out in a laboratory scale ultrasonically assisted drier. ${ }^{[24]}$ It consists of a cylindrical drying chamber whose wall acts as the ultrasound radiator, being directly connected to a piezoelectric transducer. Air flow is driven by a medium pressure fan and air velocity is controlled acting over the fan speed. The drying air is cooled down by a heat exchanger, using a glycol-water solution (45\% v/v) at $-19{ }^{\circ} \mathrm{C}$ as cooling agent. Afterwards, its temperature is controlled by an electric resistance. In order to keep the relative humidity as low as possible, the air flow is forced to pass through a desiccant material, periodically changed and regenerated (for $7 \mathrm{~h}$ at $250{ }^{\circ} \mathrm{C}$ ). In order to determine the drying kinetics, samples were weighed at pre-set times using an industrial weighing module. In order 
to avoid interferences, the fan is stopped and the sample moved out of the drying cylinder during the weighing. ${ }^{[24]}$

\section{Design of experiments}

For the purposes of investigating the effect that the main operating parameters, namely air velocity, air temperature and ultrasound power applied, as well as their reciprocal interactions, have on drying kinetics, a classical $2^{3}$ factorial design was considered in this study ${ }^{[40]}$, testing every factor at two levels, high (+) and low (-):

- Air Temperature (A): -10 and $-5^{\circ} \mathrm{C}$;

- Air velocity (B): 2 and $5 \mathrm{~m} \mathrm{~s}^{-1}$;

- Acoustic power (C): 0 and $50 \mathrm{~W}$.

This experimental design is graphically represented in Figure 1. It should be pointed out that $50 \mathrm{~W}$ is the electrical power supplied to the transducer. Taking into account the volume of the drying chamber, this corresponds to $20.5 \mathrm{~kW} \mathrm{~m}^{-3}$. The narrow intervals between temperatures was chosen to check if the expected increase of drying kinetics produced by the increase of drying temperature is so important to compensate the probable negative effect in quality of obtained. From previous results, obtained by drying cubic apple samples, ${ }^{[30]}$ air velocity is not expected to have a great influence on the drying time. For this reason, and to gain a deeper insight into ultrasonically assisted atmospheric freeze drying, another experimental factorial design was considered. In this case, a $3^{2}$ (two parameters, studied at three different levels) design was planned including, to the previously tested, an intermediate value of air temperature, $-7.5^{\circ} \mathrm{C}$, and acoustic power, $25 \mathrm{~W}\left(10.3 \mathrm{~kW} \mathrm{~m}^{-3}\right)$, as shown in Figure 2.

All of the previous tests were carried out by processing $8.8 \mathrm{~mm}$ side cubic samples. In order to investigate the effect of the sample size on the process, additional drying tests were carried out using $17.6 \mathrm{~mm}$ side cubes at $-10^{\circ} \mathrm{C}, 2 \mathrm{~m} \mathrm{~s}^{-1}$, with and without ultrasound application.

For every run the same mass load (14 $\pm 1 \mathrm{~g})$ was used, which was achieved with forty $8.8 \mathrm{~mm}$ cubes and five $17.6 \mathrm{~mm}$ cubes. The ultrasonic frequency applied in all of the experiments was $21.9 \mathrm{kHz}$. Every drying condition was tested at least three times. For each run, raw material from different eggplants was obtained to account for the material heterogeneity, ensuring the statistical significance of the results.

The significance and the magnitude of the influence of the process parameters on the drying time and, thus, on the drying rate, was investigated using the analysis of variance (ANOVA) method. The software Statgraphics ${ }^{\mathrm{TM}}$ was used for this purpose, and two levels of 
confidence value were considered: p-value of under 0.05 and p-value of under 0.01 .

\section{Mathematical modeling and estimation of kinetic parameters}

The main novelty of this study was to establish a modeling framework accounting for the real sample geometry, both for the experimental investigation of dried kinetics (where cubic samples are used), and for the industrial process (where the slices on the tray can be assumed as an infinite plane that only loses water through the upper surface). Thus no simplifying hypothesis on sample geometry (e.g. assuming the sample to be equivalent to a spherical particles, as it was done in a previous study ${ }^{[27]}$ ) was assumed. By this way, more accurate results are expected to be retrieved from the experimental investigation, and more reliable results are expected to be obtained when simulating the industrial scale unit.

In this study, the URIF model was used to model the atmospheric freeze-drying process. It assumes that two different layers can be distinguished in the samples during the freeze-drying process, namely a frozen inner core and a dried outer layer. The ice front retreats in a perfectly uniform way while ice sublimation goes on. Heat is transferred through the surface of the product, from the external air stream to the sublimation front. Ice sublimates using the amount of heat transferred and water vapor diffuses from the frozen front to the product surface and from the product surface to the drying chamber. The main hypotheses used for its derivation were:

- An ice front, parallel to the product surface, separates the frozen inner core from the outer dried layer;

- Sublimation goes on at this interface and, for this reason, it uniformly retreats;

- The process is assumed to take place in a quasi-steady state condition, thus neglecting the first transient stage, and the energy transferred to the product is used only for ice sublimation;

- No residual moisture remains in the dried product;

- The surface of the product is smooth and no change in shape is induced by the freezing/drying processes, e.g. no shrinkage occurs;

- One-dimensional gradients of temperature and water concentration were considered.

Under these conditions, the water vapor flux is directly proportional to the variation of the dried volume over time, and the global mass balance can be written as: 
$G=-\frac{d m_{w}}{d t}=\rho_{d} W_{0} \frac{d V_{d}}{d t}$

If all the heat exchanged between the flowing air and the product is used for ice sublimation, we can write that:

$Q=G \cdot \Delta H_{s}$

In order to describe in detail what happens in any time step, the local transfer equations have to be solved. These equations depend on the shape and geometry of the sample. In this case, a cubic geometry was considered for the samples. The inner frozen core was also a cube that decreased uniformly during drying, as shown in Figure 3. For a cubic system, the local mass balance in steady-state condition inside the dried layer is given by the following equation:

$$
\begin{aligned}
& \left.2 J_{w, x}\right|_{x} y z+\left.2 J_{w, y}\right|_{y} x z+\left.2 J_{w, z}\right|_{z} x y= \\
& \left.2 J_{w, x}\right|_{x+\Delta x}(y+\Delta y)(z+\Delta z)+\left.2 J_{w, y}\right|_{y+\Delta y}(x+\Delta x)(z+\Delta z)+\left.2 J_{w, z}\right|_{z+\Delta z}(x+\Delta x)(y+\Delta y)
\end{aligned}
$$

The hypotheses previously introduced imply that:

$$
\left\{\begin{array}{l}
\Delta x=\Delta y=\Delta z \\
J_{w, x}=J_{w, y}=J_{w, z}
\end{array}\right.
$$

and, thus, eq. (3) can be written as:

$$
\left.x^{2} J_{w, x}\right|_{x+\Delta x}-\left.x^{2} J_{w, x}\right|_{x}=0
$$

For an infinitesimal dried volume, it can write:

$$
\lim _{\Delta x \rightarrow 0} \frac{\left.x^{2} J_{w, x}\right|_{x+\Delta x}-\left.x^{2} J_{w, x}\right|_{x}}{\Delta x}=\frac{d}{d x}\left(x^{2} J_{w}\right)=0
$$

The water flux, $J_{w}$, is given by the Fick equation:

$$
J_{w}=-\frac{D_{w} M_{w}}{R T} \frac{d p_{w}}{d x}
$$

To obtain the value of the temperature inside the dried cake, the Fourier equation has to be solved for the specific geometry. Since the temperature difference between the ice front and that of the air is usually of a few degrees, the temperature of the solid at the ice front, $T_{i}$, is used. Assuming the following boundary conditions:

$$
\begin{cases}x=a_{0}-a_{d} & p_{w}=p_{w, i} \\ x=a_{0} & p_{w}=p_{w}^{*}\end{cases}
$$

the integration of eqs. (6) and (7) leads to: 


$$
G=24 x^{2} J_{w}=24 \frac{D_{w} M_{w}}{R T_{i}} \frac{a_{0}\left(a_{0}-a_{d}\right)}{a_{d}}\left(p_{w, i}-p_{w}^{*}\right)
$$

The water flux at the external surface is given by the following equation:

$$
G=S \alpha \frac{M_{w}}{R T_{\text {air }}}\left(p_{w}^{*}-p_{w, c}\right)
$$

where $S=24 a_{0}^{2}$ is the external surface of the sample. Then, water flow rate leaving the product is given by the following equation:

$$
G=\frac{S\left(p_{w, i}-p_{w, c}\right)}{\frac{R T_{\text {air }}}{M_{w}} \frac{1}{\alpha}+\frac{R T_{i}}{M_{w}} \frac{a_{0} a_{d}}{D_{w}\left(a_{0}-a_{d}\right)}}
$$

where it appears that the whole mass transfer resistance is given by two terms, the internal one, related to water vapor flow inside the dried layer of the product, and an external one. The substitution of eq. (11) in the mass balance given by equation (1) leads to:

$$
\frac{d V_{d}}{d t}=\frac{S}{\rho_{d} W_{0}} \frac{\left(p_{w, i}-p_{w, c}\right)}{\frac{R T_{\text {air }}}{M_{w}} \frac{1}{\alpha}+\frac{R T_{i}}{M_{w}} \frac{a_{0} a_{d}}{D_{w}\left(a_{0}-a_{d}\right)}}
$$

For the heat transfer, with an analogous procedure, we obtain:

$$
Q=\frac{S\left(T_{\text {air }}-T_{i}\right)}{\frac{1}{\beta}+\frac{a_{0} a_{d}}{\lambda\left(a_{0}-a_{d}\right)}}
$$

where two resistances in series appear: an internal one, that is a function of the solid conductivity $\lambda$, and the external one, that is a function of the heat transfer coefficient $\beta$. The substitution of eqs. (11) and (13) in eq. (2) gives the second equation of the model:

$$
\frac{\left(T_{\text {air }}-T_{i}\right)}{\frac{1}{\beta}+\frac{a_{0} a_{d}}{\lambda\left(a_{0}-a_{d}\right)}}-\frac{\left(p_{w, i}-p_{w, c}\right) \Delta H_{s}}{\frac{R T_{\text {air }}}{M_{w}} \frac{1}{\alpha}+\frac{R T_{i}}{M_{w}} \frac{a_{0} a_{d}}{D_{w}\left(a_{0}-a_{d}\right)}}=0
$$

With respect to parameters $\alpha$ and $\beta$, it has to be remarked that the Lewis analogy ${ }^{[41]}$ has been used to calculate $\beta$ from the value of $\alpha$ :

$$
\beta=\alpha c_{p, \text { air }} \rho_{\text {air }}
$$

The Differential Algebraic Equation system (DAE) given by eqs. (12) and (14) was solved in order to simulate the drying process for the cubic sample. For a certain instant of time, given the two partial pressure values, the length of the cube side, the density of the dried product, the sublimation enthalpy, the amount of water in the frozen product and, finally, the kinetic 
parameters (i.e. $D_{w}$ and $\alpha$, as $\beta$ is calculated using the Lewis analogy), it is possible to calculate the dried volume of the product and the temperature at the sublimation interface. The dried volume can be easily related to the residual moisture content by the global mass balance (eq. (1)). The drying rate calculated in this way can be compared with the experimentally measured value in order to obtain the values of external and internal transfer coefficients, $\alpha$ and $D_{w}$, that can best fit the experimental data, minimizing the following function:

$$
F=\sum_{i=1}^{N}\left(W_{\text {exp }}\left(t_{i}\right)-W_{\text {calc }}\left(t_{i}\right)\right)^{2}
$$

where $W_{\text {exp }}\left(t_{i}\right)$ is the experimentally measured moisture content at a generic instant of time $t_{i}$, and $W_{\text {calc }}\left(t_{i}\right)$ is the calculated value at the same instant of time $t_{i}$.

\section{Plant simulation and optimization}

The other novelty of the study is to provide an in silico approach to the industrial process optimization, pointing out, in a quantitative way, the effect of the operating variables on the plant productivity and on the energy consumption of the process. To the best of our knowledge such investigation was never given in the Literature, and it is of outmost importance to clearly identify the advantages and the weakness of the ultrasound assisted atmospheric freeze drying process. To this purpose, the URIF model for the flat geometry was solved in order to simulate a tunnel drier for slices of eggplant, ${ }^{[42]}$ a realistic approach to an industrial application. The slices on the tray can be assumed as an infinite plane that only loses water through the upper surface. The dryer basically consists of a parallelepiped chamber. The geometrical dimensions of the trays for the case study investigated were set arbitrarily at $2 \mathrm{~m} \mathrm{x} 1 \mathrm{~m}$ and the space between each one of the trays at $0.1 \mathrm{~m}$. The product is assumed to be cut into cylindrical slices, $10 \mathrm{~cm}$ in diameter. Every batch is supposed to be charged with $100 \mathrm{~kg}$ of fresh product. Different product thickness values were considered in the numerical simulations, as this parameter has a marked effect on the drying rate. As the total amount of product processed in each batch is constant for the sake of comparison, as is the size of each tray, once the product thickness value has been selected, the number of shelves required is calculated (and, finally, the height of the freeze-dryer). Any heterogeneity on the tray was neglected and any row of samples perpendicular to the air flux was assumed to be processed under the same conditions. In order to simulate the industrial dryer the effect 
of ultrasound on the drying kinetics is considered to be similar to the one obtained in the experiments at laboratory scale. The aim of this study was twofold: to calculate the time needed to completely dry the whole batch, as a measurement of the process productivity, and to estimate the main costs.

For the flat geometry, shown in Figure 4, the local mass balance in steady-state condition inside the dried layer is given by the following equation:

$$
\frac{d J_{w}}{d x}=0
$$

where $J_{w}$ is the water flux given by the Fick equation (eq. (7)). The integration of eqs. (17) and (7) assuming the following boundary conditions:

$$
\begin{cases}x=L_{0}-L_{d} & p_{w}=p_{w, i} \\ x=L_{0} & p_{w}=p_{w}^{*}\end{cases}
$$

leads to:

$$
G=S J_{w}=\frac{D_{w} M_{w}}{R T_{i}} \frac{S}{L_{d}}\left(p_{w, i}-p_{w}^{*}\right)
$$

The water flux written at the external surface is given by an equation identical to eq. (10). Then, the flow rate of water is given by the following equation:

$$
G=\frac{S\left(p_{w, i}-p_{w, c}\right)}{\frac{R T_{\text {air }}}{M_{w}} \frac{1}{\alpha}+\frac{R T_{i}}{M_{w}} \frac{L_{d}}{D_{w}}}
$$

Taking into account that the top surface $S$ does not change over time, and that $V_{d}=S \cdot L_{d}$, the substitution of equation (20) in the global mass balance, eq. (1), gives the first equation of the model:

$$
\frac{d L_{d}}{d t}=\frac{1}{\rho_{d} W_{0}} \frac{\left(p_{w, i}-p_{w, c}\right)}{\frac{R T_{\text {air }}}{M_{w}} \frac{1}{\alpha}+\frac{R T_{i}}{M_{w}} \frac{L_{d}}{D_{w}}}
$$

For the heat transfer, following an analogous procedure, it is obtained:

$$
Q=\frac{S\left(T_{a i r}-T_{i}\right)}{\frac{1}{\beta}+\frac{L_{d}}{\lambda}}
$$

The substitution of eqs. (20) and (22) in eq. (2) leads to the second equation of the model:

$$
\frac{\left(T_{\text {air }}-T_{i}\right)}{\frac{1}{\beta}+\frac{L_{d}}{\lambda}}-\frac{\left(p_{w, i}-p_{w, c}\right) \Delta H_{s}}{\frac{R T_{a i r}}{M_{w}} \frac{1}{\alpha}+\frac{R T_{i}}{M_{w}} \frac{L_{d}}{D_{w}}}=0
$$


If ultrasound is not applied, the water flux is supposed to be small enough so as not to greatly affect the behavior of the drier, but the enhancement of the mass transfer could reduce the driving force of the process causing a loss in productivity and leading to a heterogeneous product. To account for this problem, the tray was divided into space steps and, for each one, the Differential-Algebraic Equations system, eqs. (21) and (23), was solved in order to obtain the dried layer thickness of the row of samples inside the space steps. The dried volume can be easily related to the residual moisture content of the sample and, consequently, to the water flux inside the dried cake. Once the water flux, $G$, is known, air humidity can be updated before starting the simulation of the next space step:

$U=U_{0}+\frac{G}{m_{\text {air }}}$

The number of space steps has been calculated dividing the tray length $L_{\text {tray }}$ by the chosen length of the space step $\Delta_{x}$ :

$$
N_{p}=\frac{L_{\text {tray }}}{\Delta_{x}}
$$

One of the main problems of AFD is that a huge amount of highly dry air is needed in order to obtain the highest possible driving force. The industrial equipment generally used to dry this air is a rotary drier. Essentially, it is a big wheel full of absorbent material rotating on its axis. Generally, $75 \%$ of the wheel surface is devoted to the process of air drying, while the other $25 \%$ is used to regenerate and cool down the desiccant, namely silica gel or zeolites. In this way, the desiccant, in a relative motion with respect to the air, continuously changes and is regenerated, thus enabling a continuous mode of operation. Unfortunately, a rotating drier is rather expensive, the desiccant has to be changed with some frequency, and huge amounts of steam (low pressure steam is effective and, sometimes, an overheated heat cascade can be suitable) are necessary for regeneration. Last but not least, the surface of the drums is related to the amount of air they can process through the air velocity allowed inside the equipment and, thus, geometrical and space issues may limit the maximum amount of air that can be treated. Munters MCD 100 HPS High Performance silica-gel drier was the system chosen for this study. ${ }^{[43]}$ being its main characteristics reported in Table 1 . These data allowed evaluating the main operational costs of the equipment, namely the electric power required to move the wheel and the amount of low pressure steam required for the desiccant regeneration. The steam consumption was assumed to be constant, even when different air flows are processed, because, given a certain wheel surface, a minimum velocity is required inside the desiccant to 
avoid condensation.

The total electrical consumption of the plant is the sum of three terms: the operating costs for the rotary drier, the cost of air flow and the electric energy required for ultrasound generation. Air flow is assumed to be provided by a compressor, whose operational cost was obtained by a rough estimation of the pressure drops in the line, in the freeze drier chamber as well as in the rotary drier. An overall efficiency of 50\% was assumed for electric energy conversion. For the purposes of investigating these costs, a one factor at time design approach (one factor is changed, keeping all the others constant) was chosen. Since the air temperature can be expected to exert a marked influence on the nutritional properties of the product, it was fixed at the lowest value studied, namely $-10{ }^{\circ} \mathrm{C}$. The effect of the ultrasound intensity was considered independent of chamber shape. Thus, the values investigated for the others parameters were the following:

- Air velocity: 1, 2, 4, $6 \mathrm{~m} \mathrm{~s}^{-1}$;

- Sample thickness: 5, 10 and $15 \mathrm{~mm}$;

- Air humidity: 5, 10, 15, 20 and 30\%;

- Acoustic power: 0, 10.3 and $20.5 \mathrm{kWm}^{-3}$.

The results were compared in terms of plant productivity, kilograms of dried product per hour of processing, amount of low pressure steam (kilograms) and electric energy (kWh) for one hundred kilograms of dried product. As an index of the fixed costs of the plant, two aspects were considered: the drying chamber volume and, given the maximum volumetric flow allowed inside the rotary drier, the number of Munters MCD 100 HPS required.

\section{Results and discussion}

\section{Experimental results}

Some variability was observed in the measured drying time when the same operating conditions were tested, the standard deviation varying from $4 \%$ up to $38 \%$ (Table 2). This can be attributed to the highly heterogeneous nature of the vegetable processed. This drying time was greatly reduced when the acoustic power was applied. In fact, in drying experiments carried out at $-10^{\circ} \mathrm{C}$ and with an air velocity of $2 \mathrm{~m} \mathrm{~s}^{-1}$, a time reduction of $72 \%$ was obtained when ultrasound was applied at $25 \mathrm{~W}$ compared to non-ultrasonically assisted experiments (Figure 5). When twice the power was applied, $50 \mathrm{~W}$, the time reduction was almost $82 \%$. 
These results showed that, under these conditions, the drying time was a non-linear function of the acoustic power applied, and a large drying time reduction was also possible when working at low values of ultrasonic power.

It is also possible to highlight the interaction between sample size and ultrasound application. Thus, when drying took place without ultrasound application, doubling the side of the cube, which represents an eight-time volume increase, tripled the drying time. On the contrary, in the case of experiments carried out at an acoustic power of $50 \mathrm{~W}$, almost the same drying time was needed, regardless of the different product dimensions tested (Table 2).

The multifactorial ANOVA analysis showed that the direct effect of temperature and acoustic power on the drying kinetics was significant at 99 \% (Table 3). On the contrary, air velocity showed no significance at all, having a p-value higher than 0.3. As regards geometry and ultrasound energy factors, both the individual and the interaction effects were significant $(\mathrm{p}<0.05)$.

\section{Estimation of kinetic parameters}

The URIF model was fitted to the experimental data obtained under each drying condition tested. The results of the fitting procedure for both water vapour diffusivity and the mass transfer coefficient are reported in Table 4. As expected, the average diffusivity coefficient identified for the experiments carried out without ultrasound application at $2 \mathrm{~ms}^{-1}$, was $15 \%$ lower at $-10{ }^{\circ} \mathrm{C}$ than at $-5{ }^{\circ} \mathrm{C}$. When ultrasound was applied, a dramatic increase in the diffusivity coefficient was found. This increase masked the effect of the temperature, which turns out to be negligible in the range considered. Thus, when an ultrasound power of $25 \mathrm{~W}$ was applied, the average diffusivity coefficient increased by $380 \%$ compared to that obtained for the non-ultrasonically assisted drying experiments. When the highest power was tested (50 W), the effective diffusivity was one order of magnitude higher compared to the tests carried out without ultrasound. As for the sample size, no effect of this parameter on water diffusivity was observed because size is included in the model. However, when ultrasound was applied, it was observed that the bigger the sample size, the higher the identified diffusivity value. This points to a greater influence of ultrasound leading to a reduction in internal mass transport resistance. These preliminary results can indicate the ability of power ultrasound application to speed up the drying of samples that are bigger than the conventional size, with no side effects.

The effect of the operating conditions on the diffusivity coefficients obtained from the fitting procedure is shown in Figures 6 and 7. Thus, the air temperature had a non-significant 
effect on the identified diffusivity. The influence of the air velocity was also negligible (Figure 7). On the contrary, effective diffusivity significantly increased when the level of ultrasonic power applied rose, demonstrating a linear dependence, as also reported in the literature. $^{[34]}$

Examples of the evolution of the calculated sample weight loss using the fitted values of water diffusivity, compared with the experimentally measured values, are shown in Figure 8, underlining how adequate the proposed model is for the purposes of describing the drying rate under various operating conditions. The ability to predict the experimental drying time was also evaluated through a parity chart (Figure 9), comparing, for each set of operating conditions, the predicted drying time and the three experimentally measured values of the corresponding replicates. Taking into account the variability of the measured values of drying time, shown in Figure 9 by the horizontal error bar, the ability of the URIF model to satisfactorily describe the behaviour of an AFD process was proven.

\section{Mass transfer coefficient}

Both air velocity and the acoustic power applied influenced the mass transfer coefficient identified by the URIF model (Table 4). Since the air temperature interval investigated is just five degrees, the effect of the temperature on this parameter turned out to be negligible. It must be highlighted that, at the same air velocity applied, the mass transfer coefficient increased up to four-fold when using power ultrasound.

The data shown in Table 4 were used to obtain a correlation able to forecast this parameter. In order to be useful for scaling up the equipment from lab to industrial size, such an equation must be a function of parameters independent from the geometry. Thus, the volumetric acoustic power, $I_{a}$, defined as kilowatt per cubic meters of the drying chamber, was used, together with the Reynolds number. The mass transfer coefficient is generally related to the Reynolds number by an exponential relation in the form $S h=\operatorname{Re}^{n}$, where $n$ generally ranges from 0.5 to 1 . Here, since both Re and the acoustic power influence the value of $\alpha$, the same exponential correlation form for $I_{a}$ was used. Thus, the equation proposed was:

$$
\mathrm{Sh}=a \operatorname{Re}^{n}+b I_{a}^{m}
$$

The fitting procedure leads to obtain the following values for equation parameters: $a=1.94, n$ $=0.71, b=20.64, m=0.7$. Figure 10 shows the adequacy of equation (26) when attempting to forecast those values obtained from the study into the kinetic parameters. 


\section{Plant simulation}

With the aim of understanding if the proven ability of ultrasound to speed up the drying kinetics can make this type of plant more competitive, and using the parameters previously calculated, it was possible to simulate the behaviour of an industrial plant using the proposed mathematical model. The main outcomes of this investigation are reported in Figures 11 and 12. From these plots can state that:

- The productivity slightly improves when the air velocity increases (Figure 11, A). This can be explained by the fact that the ice sublimation causes an increase in the water concentration in the air stream through the drier. Higher air velocity represents a faster air renovation. This leads to an enhancement of the driving force and, thus, of the productivity, compared to a smaller gaseous flux.

- High air relative humidity has a negative effect on productivity (Figure 11, B). On the contrary, productivity is always higher for the ultrasound assisted process than for the traditional one.

- The thickest samples benefit more from the acoustic power applied (Figure 11, C). For $5 \mathrm{~mm}$ slices, the productivity obtained was four times greater than that obtained without US, while for the $15 \mathrm{~mm}$ samples the productivity $\left(1.1 \mathrm{~kg}_{\mathrm{dm} \mathrm{h}} \mathrm{h}^{-1}\right)$ was $530 \%$ greater than without US.

- Regardless of the energetic parameter investigated, a fourfold reduction in the operational costs can be achieved when the atmospheric freeze drying is assisted by power ultrasound (Figure 12).

- The amounts of electric energy and steam required are slightly reduced by a higher air velocity and a lower humidity (Figure 12, A and C). This result was more evident when the process was carried out without ultrasound, especially in the case of air humidity.

- The marked reduction in the drying time when the thickness is reduced dramatically affects steam consumption (SC), as shown in Figure 12, B. This effect is greater when the process is carried out with ultrasound, even if only a slight reduction is achieved going from 10.3 to $20.5 \mathrm{~kW} \mathrm{~m}^{-3}$.

The most interesting result that can be highlighted from this sensitivity analysis was that high values of air relative humidity can reduce the process productivity. However, for air velocities higher than $2 \mathrm{~m} \mathrm{~s}^{-1}$ the axial driving force variation through the drier was almost negligible.

The sample dimension limits the maximum amount of air that can be used, unless a 
higher capital investment is accepted. Furthermore, the cost of the drying tunnel increases with respect to the chosen sample thickness because of its greater volume, which almost triples when moving from 5 to $15 \mathrm{~mm}$, reducing the advantage gained by the productivity increase.

\section{Conclusions}

During the AFD of eggplant, power ultrasound application significantly reduced the drying time, being this reduction a non-linear function of the ultrasound power applied. Air temperature and size of the samples also produced a significant influence. On the contrary, air velocity did not play a significant role. The drying kinetics were successfully investigated using the Uniformly Retreating Ice Front model in order to fit the kinetic parameters involved in water vapour removal. Good results have been obtained for both kinetic fitting and prediction.

From the in silico simulation of the plant, it can be stated that power ultrasound can increase the productivity of a tunnel drier up to four or five times. This technology can help to significantly reduce the operational and fixed costs of the plant, thus enhancing the feasibility of an industrial plant. As a last result, it was proven that the axial driving force gradients, due an increased degree of dampness in the drying air, were almost negligible for every air velocity value higher than $2 \mathrm{~m} \mathrm{~s}^{-1}$, even when the highest water flux was required. Finally, it appears that thinner samples led to higher productivity due to the additional costs related to the need for bigger equipment when thicker samples are considered.

Despite the benefits that can be envisioned by simulation, some limitations lye on the practice. Nowadays the state of the art do not allow practical trials at industrial scale. It is important to develop new systems that could be used at industrial scale. Trials at bench scale are necessary to undertake this endeavor. In addition, the shape design of the drying chambers will be a must and should be considered. 


\section{Acknowledgements}

The authors acknowledge the financial support from Generalitat Valenciana (PROMETEOII/2014/005) and INIA (RTA2015-00060-C04-02). 


\section{List of symbols}

a

$a_{0}$

$a_{d}$

b

$C_{p, \text { air }}$

$D_{w}$

EC

F

G

$\Delta H_{S}$

$I_{a}$

$J_{q}$

$J_{w}$

$J_{w, x}$

$\left.J_{w, x}\right|_{x}$

$\left.J_{w, x}\right|_{x+\Delta x}$

$J_{w, y}$

$\left.J_{w, y}\right|_{y}$

$\left.J_{w, y}\right|_{y+\Delta y}$

$J_{w, z}$

$\left.J_{w, z}\right|_{z}$

$\left.J_{w, z}\right|_{z+\Delta z}$

$L_{0}$

$L_{d}$

$L_{\text {tray }}$

Parameter used in eq. 26

Characteristic dimension of cubic samples (half side), $\mathrm{m}$

Characteristic dimension of dried product, $\mathrm{m}$

Parameter used in eq. 26

Heat capacity of the air, $\mathrm{J} \mathrm{kg}^{-1} \mathrm{~K}^{-1}$

Effective diffusivity of water vapor, $\mathrm{m}^{2} \mathrm{~s}^{-1}$

Electricity consumption, $\mathrm{kWh} 100 \mathrm{~kg}_{\text {dried matter }}^{-1}$

Function to be minimized, $\left(\mathrm{kg}_{\mathrm{w}} \mathrm{kg}_{\text {dried matter }}^{-1}\right)^{2}$

Water flow rate, $\mathrm{kg} \mathrm{s}^{-1}$

Sublimation enthalpy of ice, $\mathrm{J} \mathrm{kg}^{-1}$

Volumetric acoustic power, $\mathrm{W} \mathrm{m}^{-3}$

Heat flux, $\mathrm{W} \mathrm{m}^{-2}$

Water flux, $\mathrm{kg} \mathrm{s}^{-1} \mathrm{~m}^{-2}$

water flux in the $x$ direction, $\mathrm{kg} \mathrm{s}^{-1} \mathrm{~m}^{-2}$

water flux in the $x$ direction, at position $x, \mathrm{~kg} \mathrm{~s}^{-1} \mathrm{~m}^{-2}$

water flux in the $x$ direction, at position $x+\Delta x, \mathrm{~kg} \mathrm{~s}^{-1} \mathrm{~m}^{-2}$

water flux in the $y$ direction, $\mathrm{kg} \mathrm{s}^{-1} \mathrm{~m}^{-2}$

water flux in the $y$ direction, at position $y, \mathrm{~kg} \mathrm{~s}^{-1} \mathrm{~m}^{-2}$

water flux in the $y$ direction, at position $y+\Delta y, \mathrm{~kg} \mathrm{~s}^{-1} \mathrm{~m}^{-2}$

water flux in the $z$ direction, $\mathrm{kg} \mathrm{s}^{-1} \mathrm{~m}^{-2}$

water flux in the $z$ direction, at position $z, \mathrm{~kg} \mathrm{~s}^{-1} \mathrm{~m}^{-2}$

water flux in the $z$ direction, at position $z+\square z, \mathrm{~kg} \mathrm{~s}^{-1} \mathrm{~m}^{-2}$

Thickness of the product, $\mathrm{m}$

Thickness of the dried product, $\mathrm{m}$

Length of a single tray of the drier, $m$ 


\begin{tabular}{|c|c|}
\hline$m_{\text {air }}$ & Air mass flow, $\mathrm{kg} \mathrm{s}^{-1}$ \\
\hline$m$ & Parameter used in eq. 26 \\
\hline$m_{w}$ & Mass of water in the product, kg \\
\hline$M_{w}$ & Molecular weight of water, $\mathrm{kg} \mathrm{kmol}^{-1}$ \\
\hline$n$ & Parameter used in eq. 26 \\
\hline$N$ & Number of samples considered in the best fit procedure (eq. 16) \\
\hline$N_{p}$ & Number of space step for plant simulation \\
\hline$p_{w}$ & Water vapor partial pressure, Pa \\
\hline$p_{w}^{*}$ & Water vapor partial pressure at the external surface of the product, $\mathrm{Pa}$ \\
\hline$p_{w, c}$ & Water vapor partial pressure in the drying chamber, Pa \\
\hline$p_{w, i}$ & Water vapor partial pressure at the sublimation interface, Pa \\
\hline$Q$ & Heat flow rate, $\mathrm{W}$ \\
\hline$R$ & Ideal gas constant, $\mathrm{J}$ kmol ${ }^{-1} \mathrm{~K}^{-1}$ \\
\hline Re & Reynolds number \\
\hline$S$ & Surface of product, $\mathrm{m}^{2}$ \\
\hline$S C$ & Steam consumption, $\mathrm{kg}_{\text {vapour }} 100 \mathrm{~kg}_{\text {dried matter }}^{-1}$ \\
\hline Sh & Sherwood number \\
\hline$T$ & Temperature, K \\
\hline$t$ & Time, s \\
\hline$T_{\text {air }}$ & Air temperature, $\mathrm{K}$ \\
\hline$T_{i}$ & Temperature at the sublimation interface, $\mathrm{K}$ \\
\hline$U$ & Air specific humidity, $\mathrm{kg}_{\mathrm{w}} \mathrm{kg}_{\text {dried air }}^{-1}$ \\
\hline$U_{0}$ & Inlet air specific humidity, $\mathrm{kg}_{\mathrm{w}} \mathrm{kg}_{\text {dried air }}^{-1}$ \\
\hline$V_{d}$ & Volume of the dried product, $\mathrm{m}^{3}$ \\
\hline Vair & Air velocity, $\mathrm{m} \mathrm{s}^{-1}$ \\
\hline$W_{0}$ & Initial water content in the product, $\mathrm{kg}_{\mathrm{w}} \mathrm{kg}_{\text {dried matter }}^{-1}$ \\
\hline$W_{\text {calc }}$ & Calculated water content in the product, $\mathrm{kg}_{\mathrm{w}} \mathrm{kg}_{\text {dried matter }}^{-1}$ \\
\hline$W_{\text {exp }}$ & Calculated water content in the product, $\mathrm{kg}_{\mathrm{w}} \mathrm{kg}_{\text {dried matter }}^{-1}$ \\
\hline$x, y, z$ & Axial coordinate, $\mathrm{m}$ \\
\hline
\end{tabular}

Greek letters

$\alpha$

Mass transfer coefficient, $\mathrm{m} \mathrm{s}^{-1}$ 
$\beta$

$\Delta_{x}$

$\lambda$

$\rho_{\text {air }}$

$\rho_{d}$

$\sigma_{D_{w}}^{2}$

$\sigma_{\alpha}^{2}$

Abbreviations

AFD

EC

SC

URIF
Heat transfer coefficient, $\mathrm{W} \mathrm{m}^{-2} \mathrm{~K}^{-1}$

Space step, $\mathrm{m}$

Heat conductivity of the dried solid, $\mathrm{W} \mathrm{m}^{-1} \mathrm{~K}^{-1}$

Air density, $\mathrm{kg} \mathrm{m}^{-3}$

Dried product density, $\mathrm{kg} \mathrm{m}^{-3}$

Standard deviation of the calculated mass transfer coefficient

Standard deviation of the calculated mass transfer coefficient
C

Atmospheric freeze-drying

Electricity consumption, $\mathrm{kWh} / 100 \mathrm{~kg} d \mathrm{~m}$

Steam consumption, kg/100 kgdm

Uniformly retreating ice front 


\section{References}

1. Meryman, H. T. Sublimation: Freeze drying without vacuum. Science 1959, 130, 628629.

2. Claussen, I. C.; Ustad, T. S.; Strommen I.; Walde, P. M. Atmospheric freeze drying- A review. Drying Technology 2007, 25, 957-967.

3. Rey, L. Glimpses in the realm of freeze-drying: Classical issues and new venture. In: Freeze-drying/lyophilization of pharmaceuticals and biological products, Rey, L., May, J. C. eds. Informa Healthcare, New York, 2010; 1-28.

4. Wolff, E.; Gibert, H. Atmospheric freeze drying, Part1: Design, experimental investigation and energy saving advantages. Drying Technology 1990, 8, 385-404.

5. Strommen, I.; Alves-Filho, O.; Eikevik, T. M. Atmospheric freeze drying with heat pumps - A new alternative for high quality dried food products, in; Proceedings of the $3^{\text {rd }}$ Nordic Drying Conference, Eikevik, T. M., Alves-Filho, O., Strommen, I. eds, Karlstad, 15-17 June, 2005.

6. Alves-Filho, O. Combined innovative heat pump drying technologies and new cold extrusion techniques for production of instant foods. Drying Technology 2002, 20, 1579-1610.

7. Di Matteo, P.; Donsì, G.; Ferrari , G. The role of heat and mass transfer in atmospheric freeze-drying of food in fuidized bed. Journal of Food Engineering 2003, 59, 267-275.

8. Rahman, S. M. A.; Mujumdar, A.S. A novel atmospheric freeze-drying system using a vibro-fluidized bed with adsorbent. Drying Technology 2008, 26, 393-403.

9. Fissore, D.; Coletto, M. M.; Barresi, A. A. Atmospheric food freze-drying: challanges and opportunities. New Food 2013, 16, 9-12.

10. Legay, M.; Gondrexon, N.; Le Person, S.; Boldo, P.; Bontemps, A. Enhancement of heat transfer by ultrasound: review and recent advantages. International Journal of Chemical Engineering, 2011, Article ID 670108, 17 pages.

11. Garcia-Pérez, J. V.; Cárcel, J. A.; Mulet, A.; Riera, E.; Gallego-Juarez, J. Power ultrasonics: Application of high-intensity ultrasounds, in: Ultrasonic drying for food preservation, Gallego-Juarez, J. A., Graff, K.F. eds., Elsevier, Cambridge, 2015; 875910.

12. Gallego-Juarez, J. A.; Riera, E.; De la Fuente, S.; Rodriguez-Corral, G.; Acosta, V. M.; Blanco, A. Application of high-power ultrasound for dehydration of vegetables: 
processes and technology. Drying Technology 2007, 25, 1893-1901.

13. Gallego-Juarez, J. A.; Rodriguez-Corral, G.; Galvez-Moraleda, J. C.; Yang, T. A new high-intensity ultrasonic technology for food dehydration. Drying Technology 1999, 17, 597-608.

14. Gallego-Juarez, J. A.; Rodriguez-Corral, G.; Acosta, V. M.; Riera, E. Power ultrasonic trasducers with extensive radiators for industrial processing. Ultrasonics Sonochemistry 2010, 17, 953-964.

15. Kowalski, S.J.; Mierzwa, D. US-assisted convective drying of biological materials. Drying Technology 2015, 33, 1601-1613.

16. Liang, H. Modelling of ultrasound assisted and osmotically induced diffusion in plant tissue. PhD Thesis, Purdue University, 1993.

17. Floros, J. D.; Liang, H. Acoustically assisted diffusion through membranes and biomaterials. Food Technology 1994, 48, 79-84.

18. Santacatalina, J. V.; Contreras, M.; Simal, S.; Cárcel, J. A.; Garcia-Perez, J. V. Impact of applied ultrasonic power on the low temperature drying of apple. Ultrasonic Sonochemistry 2016, 28, 100-109.

19. Sabarez, H.T.; Gallego-Juárez, J.A.; Riera, E. Ultrasonic-assisted convective drying of apple slices. Drying Technology 2012, 30, 989-997.

20. Lighthill, S. J. Acoustic streaming, Journal of Sound and Vibration 1978, 61, 391-418.

21. Santacatalina, J. V.; Rodríguez, O.; Simal, S.; Cárcel J. A.; Mulet A.; Garcia-Perez J. V. Ultrasonically enhanced low-temperature drying of apple: Influence on drying kinetics and antioxidant potential. Journal of Food Engineering 2014, 138, 35-44.

22. Moreno, C.; Brines, C.; Mulet, A.; Rosselló, C; Cárcel, J.A. Antioxidant Potential of atmospheric freeze dried apples as affected by ultrasound application and sample surface. Drying Technology 2016, Accepted manuscript DOI: $10.1080 / 07373937.2016 .1256890$

23. Santacatalina, J.V.; Soriano, J.R.; Carcel J.A.; Garcia-Perez, J.V. Influence of air velocity and temperature on ultrasonically assisted low temperature drying of eggplant. Food and Bioproducts Processing. In press (DOI: 10.1016/j.fbp.2016.07.010).

24. Garcia-Perez, J. V.; Cárcel, J. A.; Rossello, C.; Riera, E.; Mulet, A. Intensification of low-temperature drying by using ultrasound. Drying Technology 2012, 30, 1199-1208.

25. Bantle, M.; Eikevik, T.M. Parametric study of high-intensity ultrasound in the atmospheric freeze drying of peas. Drying Technology 2011, 29, 1230-1239.

26. Alves-Filho, O.; Eikevik, T. M.; Mulet, A.; Garau, C.; Rossello, C. Kinetics and mass 
transfer during atmospheric freeze drying of red pepper. In: Proceedings of the $15^{\text {th }}$ International drying symposium (IDS 2006), Budapest, 20-23 August 2006.

27. Bantle, M.; Bergvik, M.; Rustad, T. Lipid changes and lipid oxidation in Calanus Finmarchicus vacuum, atmospheric and nitrogen freeze drying. In: Proceedings of the $17^{\text {th }}$ International drying symposium (IDS 2010), Magdeburg, 3-6 October 2010.

28. Ozuna, C.; Carcel, J. A.; Walde, P. M.; Garcia-Perez, J. V. Low-temperature drying of salted cod (Gadus morhua) assisted by high power ultrasound: Kinetics and physical properties. Innovative Food Science and Emerging Technologies 2014, 23, 146-155.

29. Santacatalina, J. V.; Guerrero, M. E.; Garcia-Perez, J. V.; Mulet, A.; Cárcel, J. A. Ultrasonically assisted low-temperature drying of desalted codfish. LWT-Food Science and Technology 2016, 65, 444-450.

30. Santacatalina, J. V.; Fissore, D.; Cárcel, J. A.; Mulet, A.; Garcia-Perez, J. V. Modelbased investigation into atmospheric freeze drying assisted by power ultrasound. Journal of Food Engineering 2015, 151, 7-15.

31. Akpinar, E. K.; Bicer, Y. Modelling of the drying of eggplants in thin-layers. International Journal of Food Science and Technology 2005, 40, 273-281.

32. Bantle, M.; Kolsaker, K.; Eikevik, T. M.; Modification of the Weibull distribution for modeling the atmospheric freeze drying of food. Drying Technology 2011, 29, 11611169.

33. Crank, J. The mathematics of diffusion. Claredon Press, Oxford, UK, 1975.

34. Ozuna, C.; Cárcel, J. A.; Santacatalina, J. V.; Mulet, A.; Garcia-Perez, J. V. Textural properties of vegetables: a key parameter on ultrasonic assisted convective drying, in: Proceedings of the $11^{\text {th }}$ International Congress of Engineering and Food, Athens, 22-26 May, 2011.

35. Santacatalina, J. V.; Rodriguez, O.; Simal, S.; Cárcel J. A.; Mulet A.; Garcia-Perez, J. V. Ultrasonically enhanced low-temperature drying of apple: Influence on drying kinetics and antioxidant potential. Journal of Food Engineering 2014, 138, 35-44.

36. Wollf, E.; Gibert, H. Atmospheric freeze drying Part 2: Modelling drying kinetics using adsorption isotherms. Drying Technology 1990, 8, 405-428.

37. Li, S.; Stawczyk, I.; Zbcinski, I. CFD model of apple atmospheric freeze drying at low temperature. Drying Technology 2007, 25, 1331-1339.

38. Warning, A. D.; Arquiza, J. M. R.; Datta, A. K. A multiphase porous medium transport model with distributed sublimation front to simulate vacuum freeze drying. Food and Bioproducts Processing 2015, 94, 637-648. 
39. Chen, N.C.; Li, H. M. Cultivation and seed production of eggplants. Training workshop on vegetable cultivation and seed production technology. Shanhua, Tainan: AVRDC, 1997, 1-12.

40. Montgomery, D. C. Design and analysis of experiments, 5th edition. John Wiley \& Sons, New York, 2001.

41. Perry, R. H.; Green, D. W. Perry's chemical Engineering Handsbook. McGraw-Hill. London, 2008.

42. Claussen, I. C.; Andresen, T.; Eikevik, T. M.; Strommen, I. Atmospheric freeze dryingModelling and simulation of a tunnel dryer. Drying Technology 2007, 25, 1959-1965.

43. Munters, https://www.munters.com/en/munters/products/dehumidifiers/mcd100/ (accessed on September 20 $0^{\text {th }}$, 2016). 


\section{List of Tables}

Table 1. Main characteristics of the Munters MCD100 considered in this study for air drying.

Table 2. Mean values of the drying time, and their relative standard deviation, obtained experimentally for each set of operating conditions tested.

Table 3. p-value and Fishers Least Significant Difference (LSD) for the values of drying time obtained experimentally.

Table 4. Values of the diffusivity coefficient and of the mass transfer coefficient obtained looking for the best-fit between the experimentally measured and the calculated values of moisture content vs. time (eq. 16). 


\section{Figure Captions}

Figure 1. Graphical representation of the $2^{3}$ factorial design used to investigate the main factors of the process.

Figure 2. Graphical representation of the $3^{2}$ factorial design used to investigate the influence of temperature and acoustic power on drying kinetics.

Figure 3. Cubic geometry for the URIF modified model.

Figure 4. Flat surface detail for the URIF model.

Figure 5. Weight loss in the sample at different levels of applied acoustic power ( $\mathbf{m :} 0 \mathrm{~W} ; \boldsymbol{\Delta}$ : $25 \mathrm{~W}$; •: $50 \mathrm{~W}), T_{\text {air }}=-10^{\circ} \mathrm{C}, v_{\text {air }}=2 \mathrm{~m} \mathrm{~s}^{-1}$.

Figure 6. Values of the effective water diffusivity obtained under different operating conditions (grey bars: $T_{\text {air }}=-10^{\circ} \mathrm{C}$; empty bars: $T_{\text {air }}=-5^{\circ} \mathrm{C}$ ); $v_{\text {air }}=2 \mathrm{~m} \mathrm{~s}^{-1}$.

Figure 7. Values of the effective water diffusivity obtained under different operating conditions (grey bars: $v_{\text {air }}=2 \mathrm{~m} \mathrm{~s}^{-1}$; empty bars: $v_{\text {air }}=5 \mathrm{~m} \mathrm{~s}^{-1}$ ); US power $=0 \mathrm{~W}$.

Figure 8. Comparison between the experimentally measured (symbols) and the calculated (lines) weight loss values in the product being freeze-dried under different operating conditions: 0, 25 and $50 \mathrm{~W}$ with $8.8 \mathrm{~mm}$ side cubic samples and $0 \mathrm{~W}$ with $17.6 \mathrm{~mm}$ side cubic samples.

Figure 9. Parity chart for the drying time obtained under various operating conditions (a zoom of the bottom left part of the chart is shown in the right hand graph). Symbols refer to the mean value of the drying time obtained experimentally.

Figure 10. Parity chart for the mass transfer coefficient obtained under various operating conditions. 
Figure 11. Plant productivity as a function of air velocity (Graph A), relative humidity (Graph B) and sample thickness (Graph C) when different ultrasound power values are

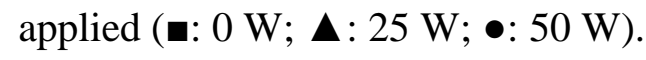

Figure 12. Steam Consumption (SC) as a function of air velocity (Graph A) and sample thickness (Graph B) and Electricity Consumption (EC) as a function of the relative humidity (Graph C) when different ultrasound power values are applied (п: $0 \mathrm{~W} ; \mathbf{\Delta}: 25 \mathrm{~W}$; •: $50 \mathrm{~W}$ ). 
Table 1

\section{Munters MCD 100}

\section{Characteristics}

\begin{tabular}{rr}
\hline Working temperature & $-20 / 40{ }^{\circ} \mathrm{C}$ \\
Electrical protection class & IP 33 \\
Nominal air flux & $10000 \mathrm{~m}^{3} \mathrm{~h}^{-1}$ \\
Net installed power & $136 \mathrm{~kW}(50 \mathrm{~Hz})$ \\
Vapour 3 bar consumption & $48 \mathrm{~g} \mathrm{~s}^{-1}$ \\
Vapour 5 bar consumption & $49 \mathrm{~g} \mathrm{~s}^{-1}$ \\
Static pressure available & $300 \mathrm{~Pa}$ \\
\hline
\end{tabular}


Table 2

\begin{tabular}{|c|c|c|c|c|c|}
\hline \multicolumn{4}{|c|}{ Operating conditions tested } & \multirow{3}{*}{$\begin{array}{c}\text { Drying time } \\
\text { [h] }\end{array}$} & \multirow{3}{*}{$\begin{array}{l}\sigma^{2} \\
{[\%]}\end{array}$} \\
\hline$T_{\text {air }}$ & $V_{\text {air }}$ & US power & Size & & \\
\hline$\left[{ }^{\circ} \mathrm{C}\right]$ & {$\left[\mathrm{m} \mathrm{s}^{-1}\right]$} & {$[W]$} & {$[\mathrm{mm}]$} & & \\
\hline-10 & 2 & 0 & 8.8 & 15.3 & 8.7 \\
\hline-10 & 2 & 25 & 8.8 & 3.7 & 10.4 \\
\hline-10 & 2 & 50 & 8.8 & 2.8 & 17.9 \\
\hline-10 & 5 & 0 & 8.8 & 14.1 & 4.2 \\
\hline-10 & 5 & 50 & 8.8 & 3.2 & 29.6 \\
\hline-5 & 2 & 0 & 8.8 & 11.8 & 8.09 \\
\hline-5 & 2 & 25 & 8.8 & 2.3 & 30.0 \\
\hline-5 & 2 & 50 & 8.8 & 2.6 & 9.2 \\
\hline-5 & 5 & 0 & 8.8 & 9.6 & 29.0 \\
\hline-5 & 5 & 50 & 8.8 & 2.4 & 38.4 \\
\hline-7.5 & 2 & 0 & 8.8 & 11.0 & 19.3 \\
\hline-7.5 & 2 & 50 & 8.8 & 1.5 & 11.3 \\
\hline-10 & 2 & 0 & 17.6 & 44.9 & 19.0 \\
\hline-10 & 2 & 50 & 17.6 & 3.7 & 22.7 \\
\hline
\end{tabular}


Table 3

\begin{tabular}{rrr} 
Factor & p-value & LSD interval \\
Temperature & 0.002 & $99 \%$ \\
Air velocity & 0.33 & NS \\
Ultrasound power & 0.0 & $99 \%$ \\
Geometry & 0.0 & $99 \%$ \\
Second order geometry/US & 0.0 & $99 \%$ \\
power & & \\
\hline
\end{tabular}


Table 4

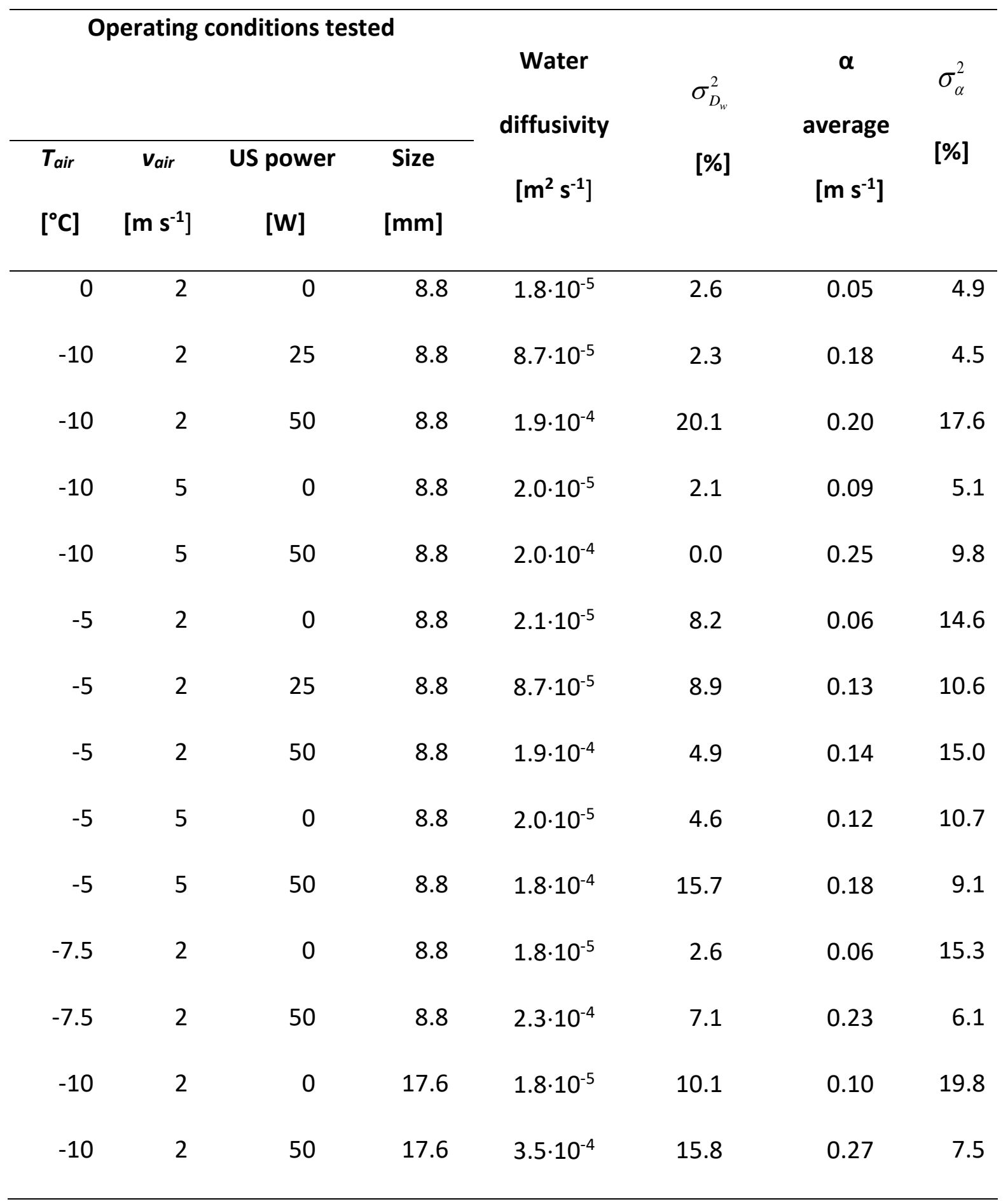




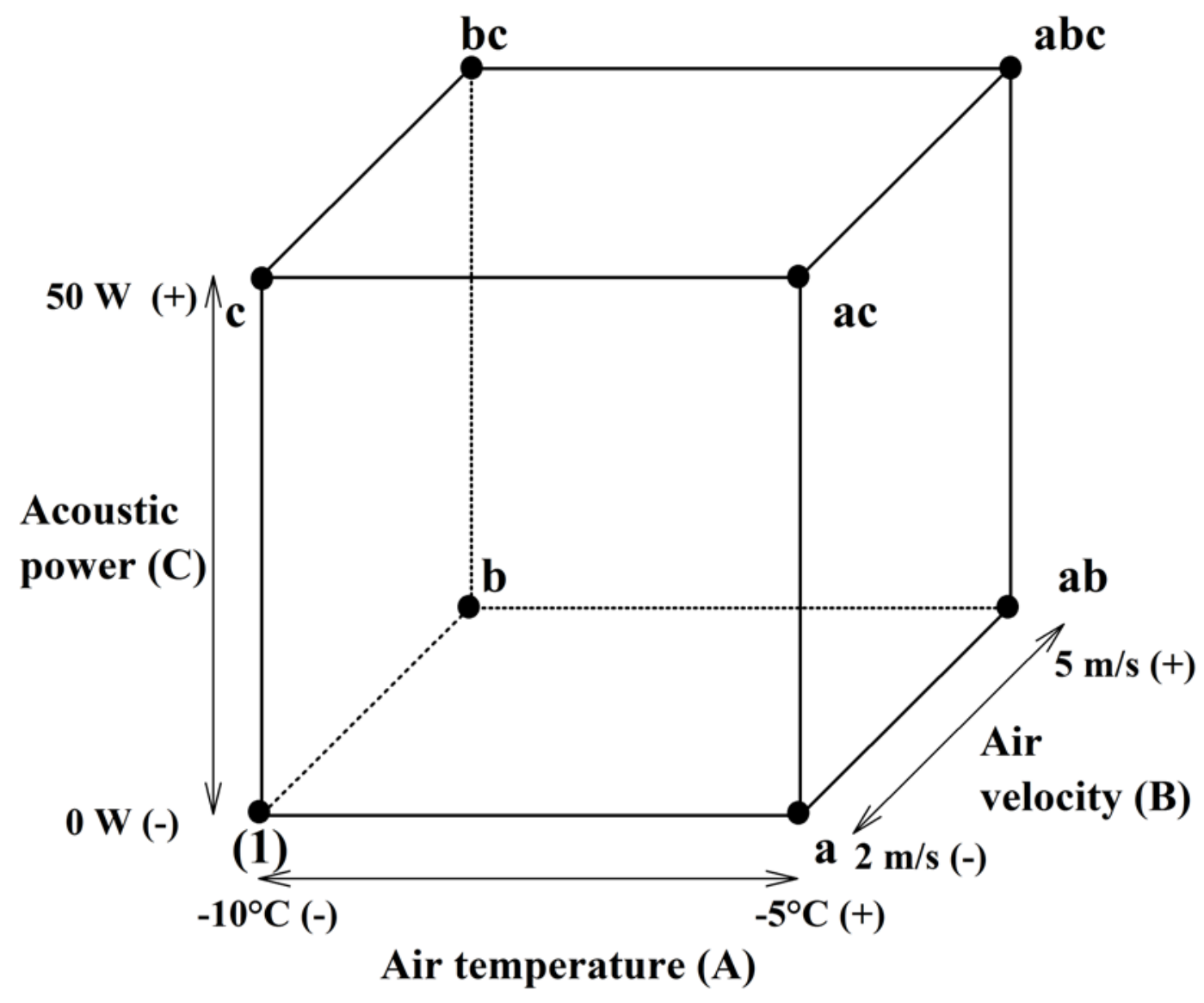




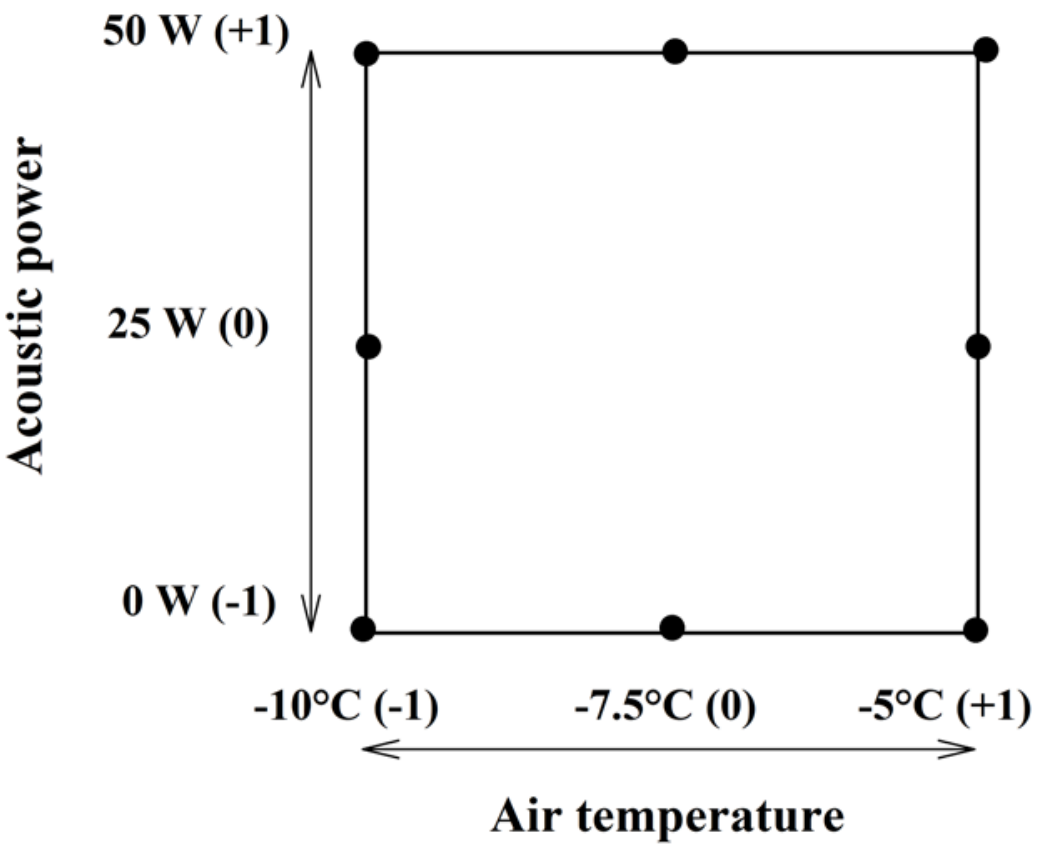




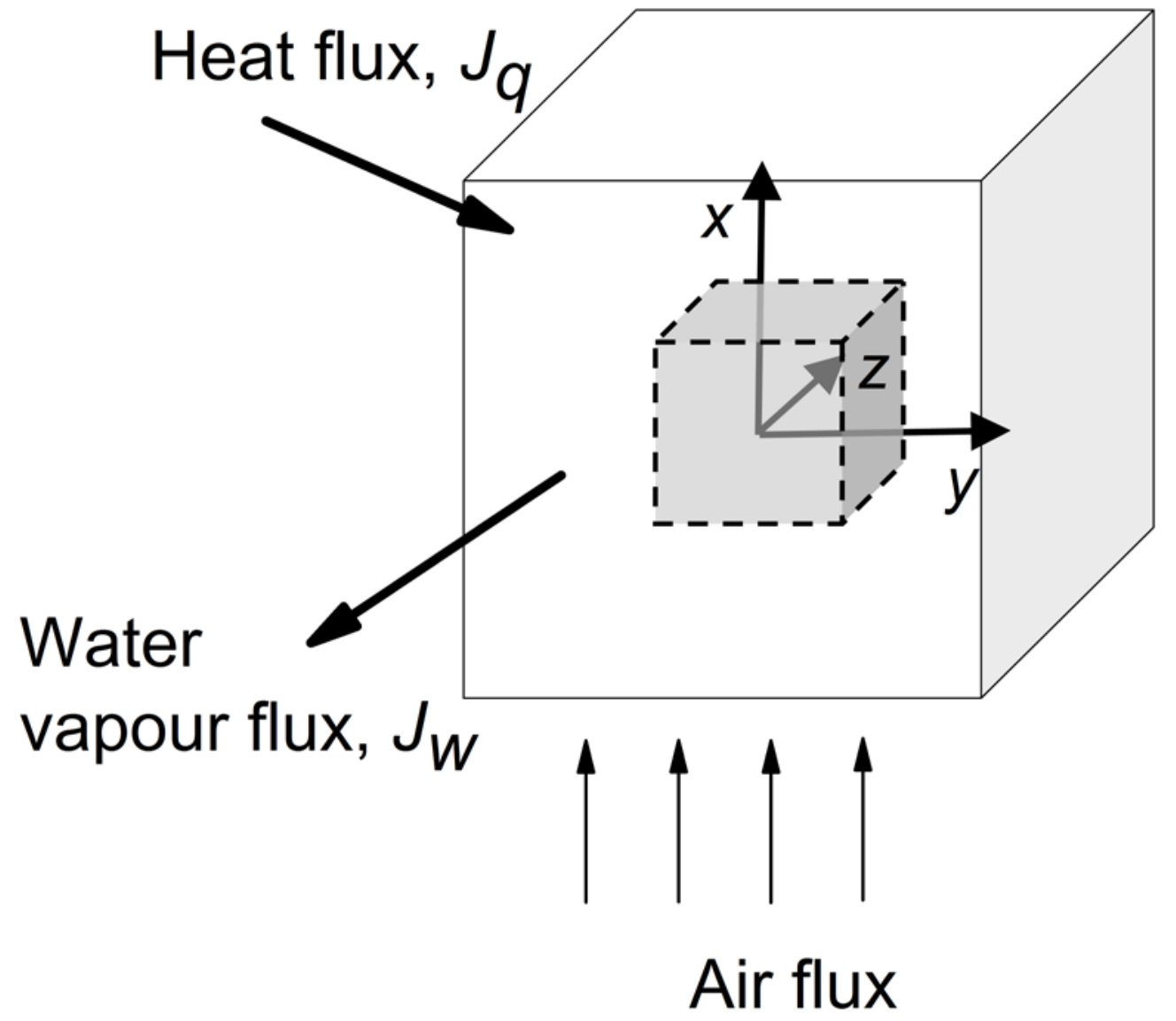




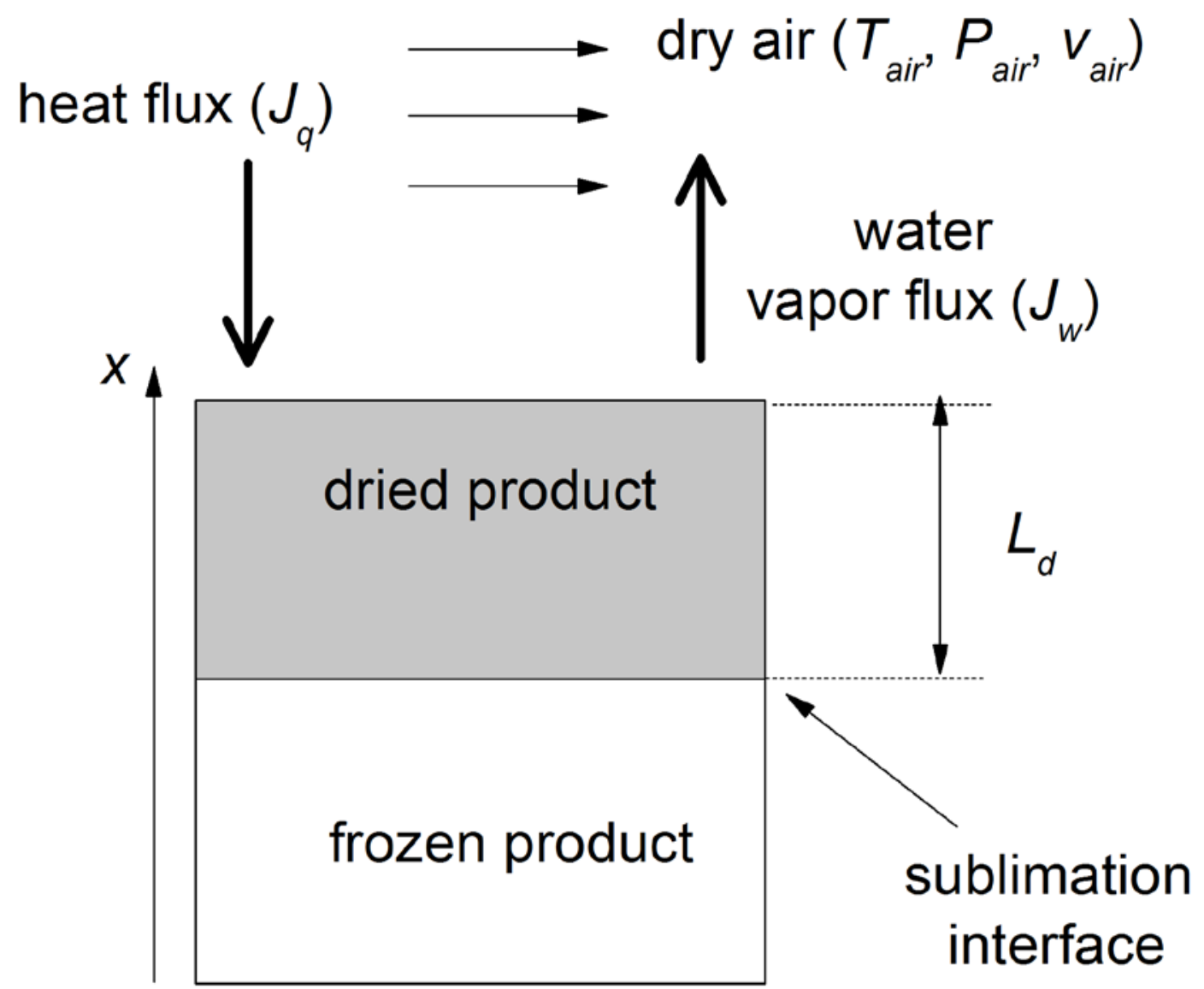




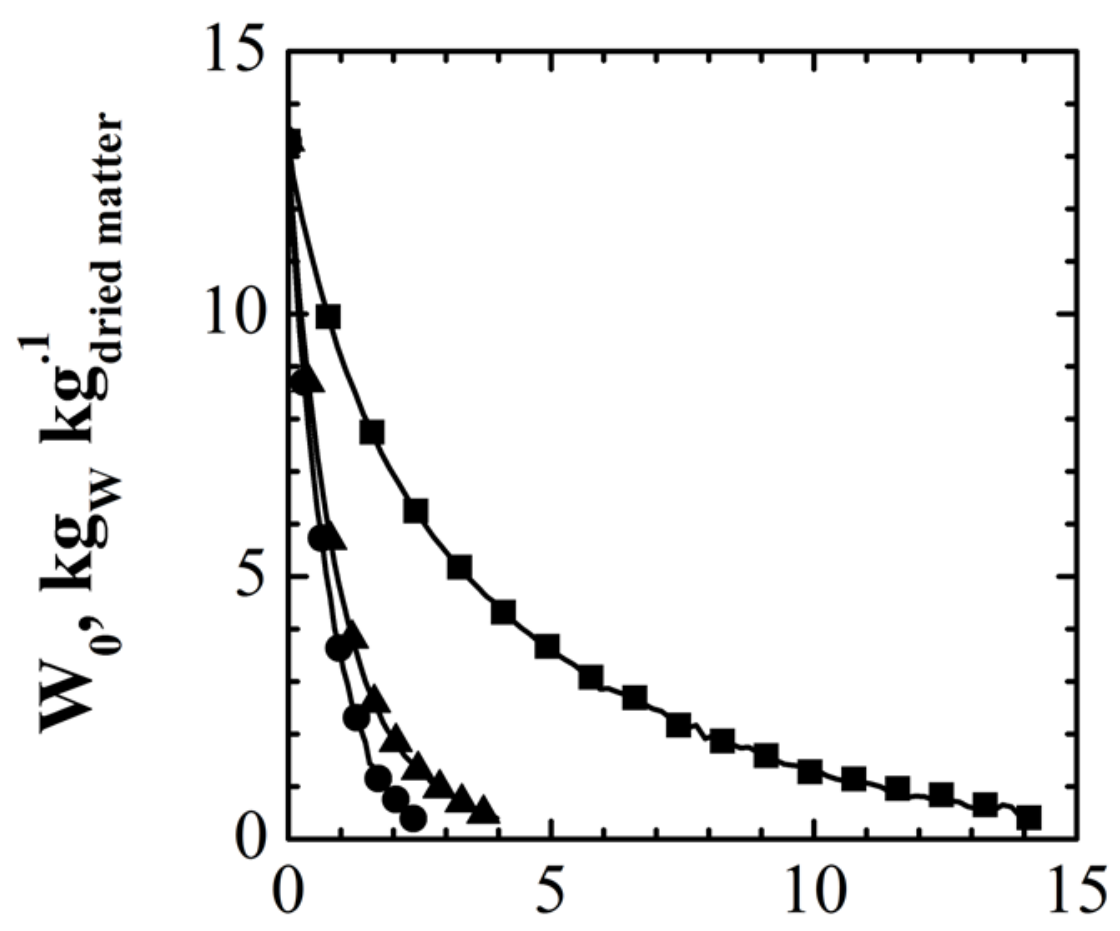

Time, h 


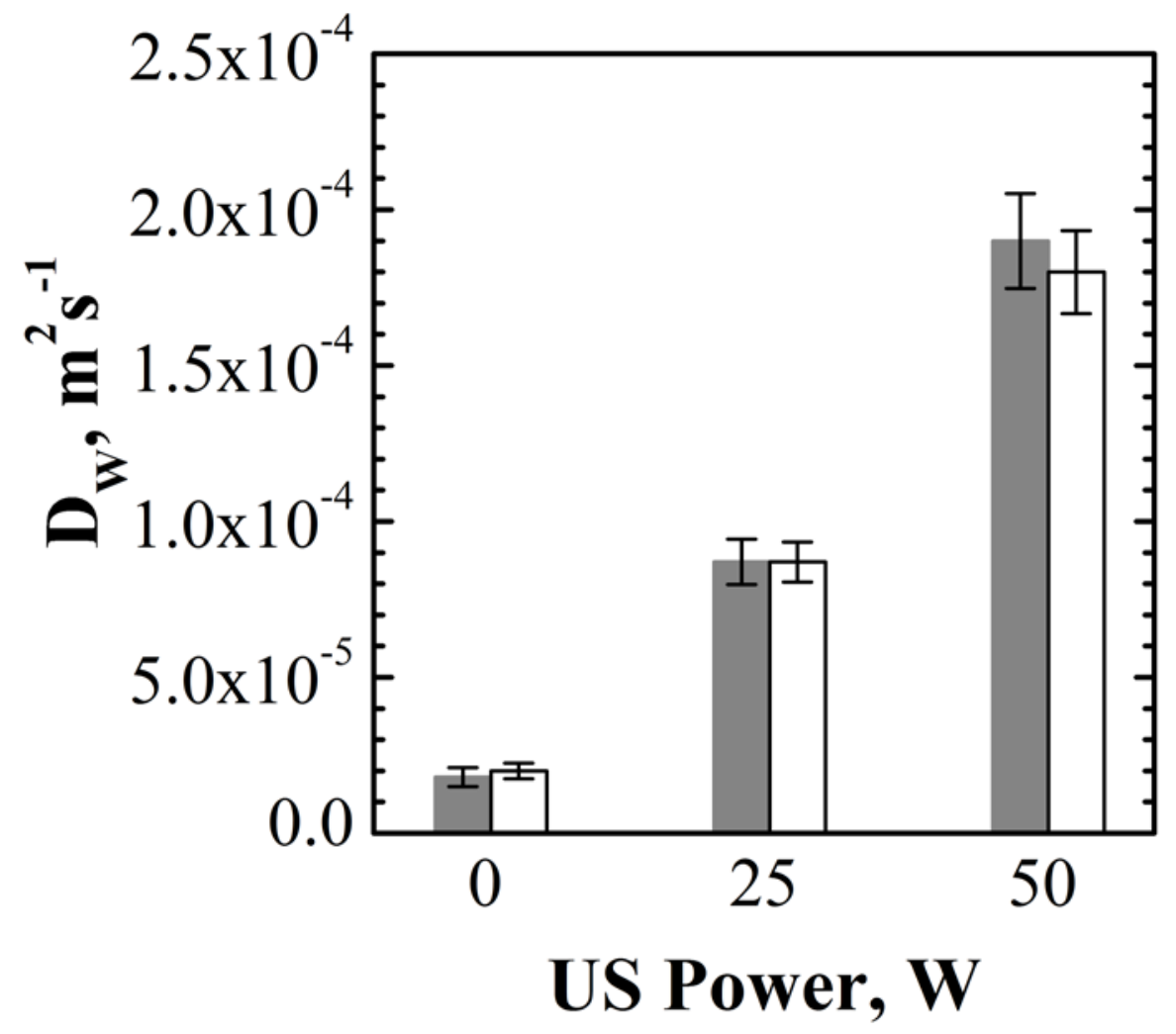




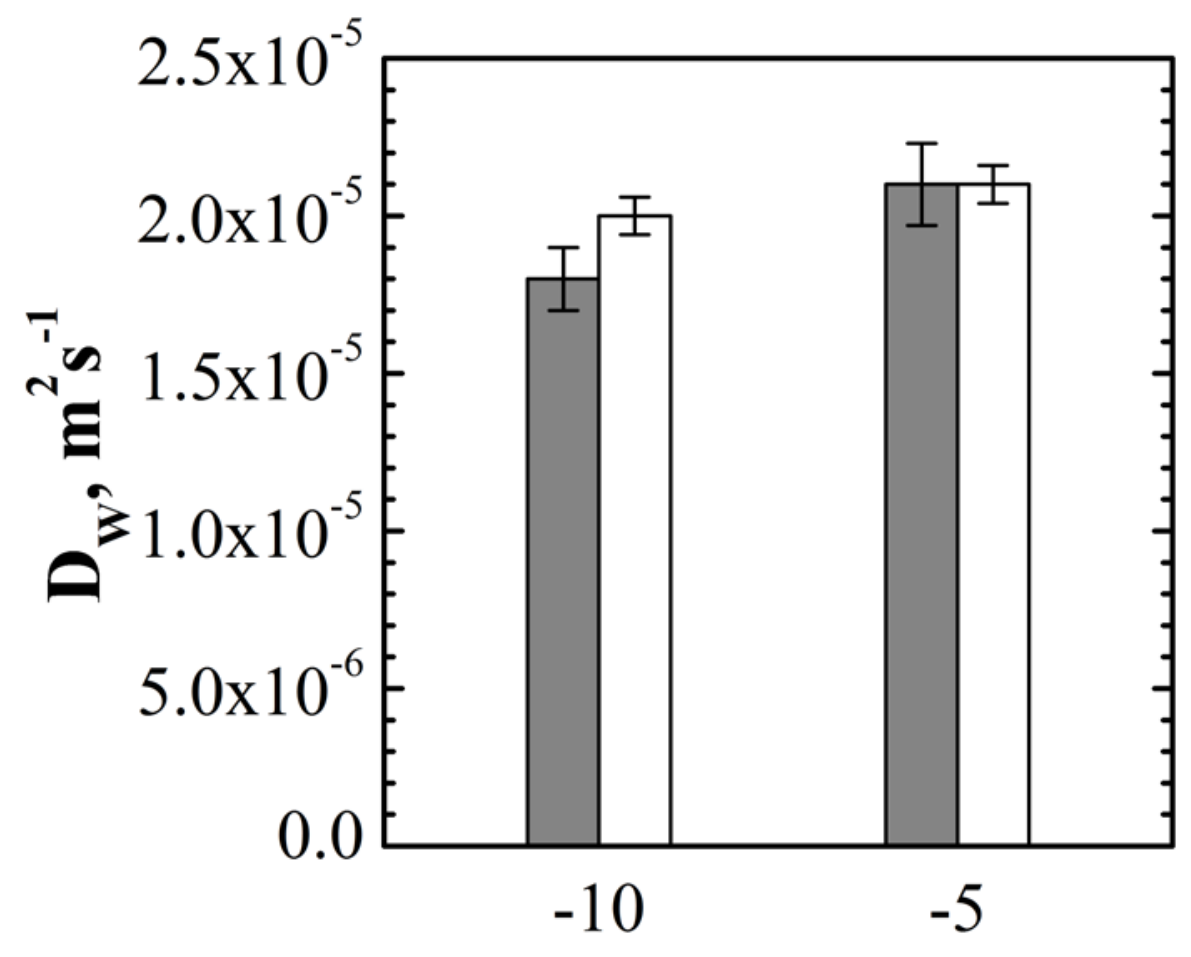

Temperature, ${ }^{\circ} \mathrm{C}$ 


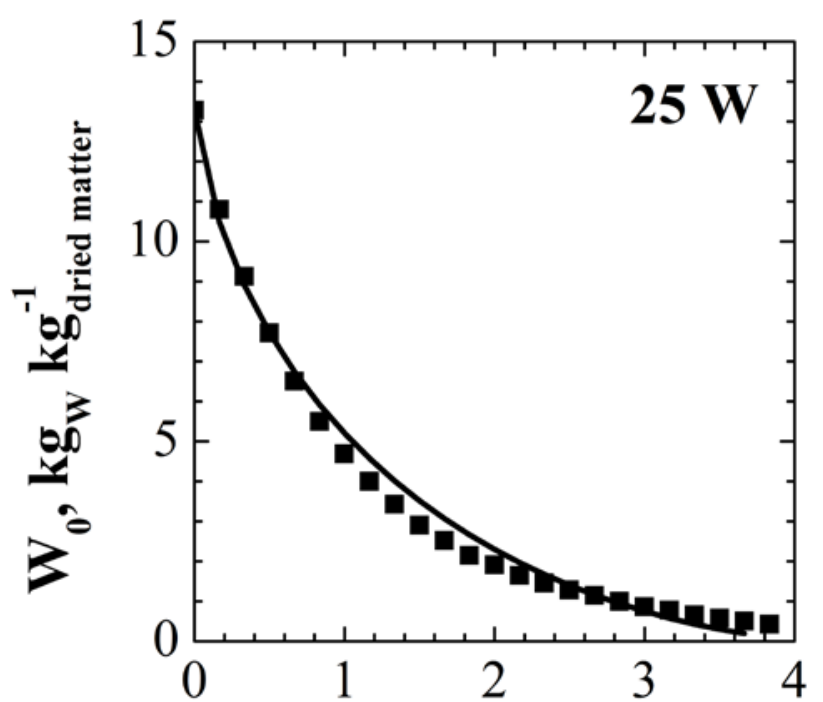

Time, h

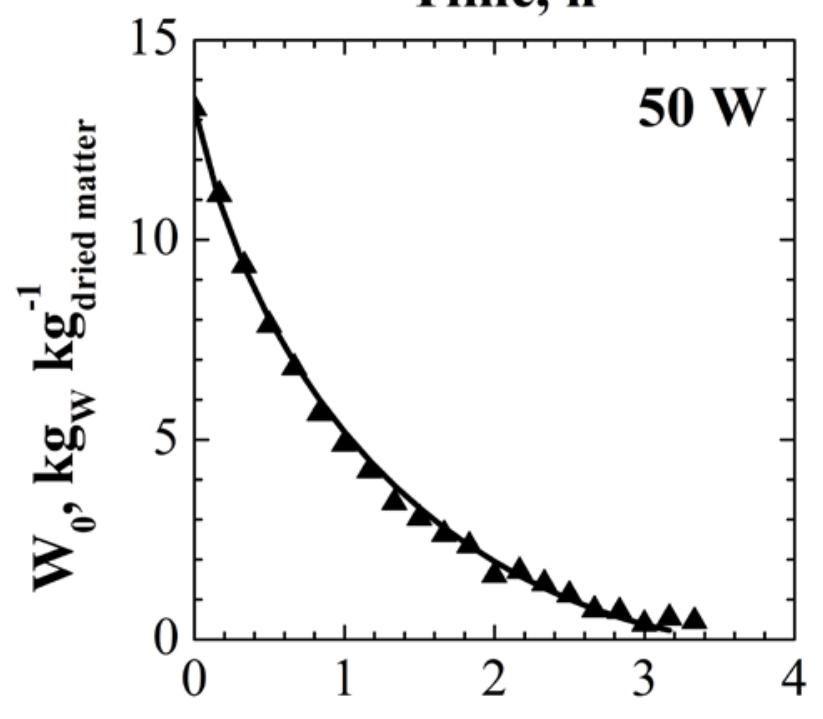

Time, h

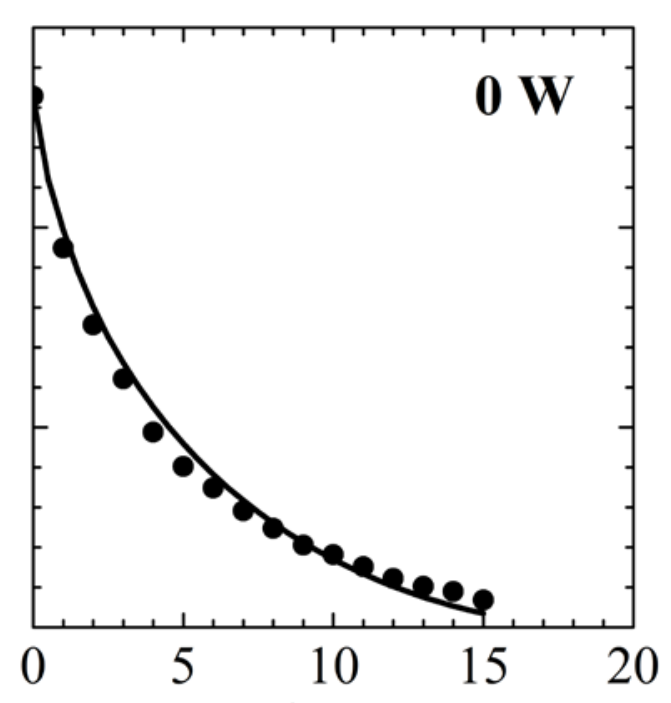

Time, h

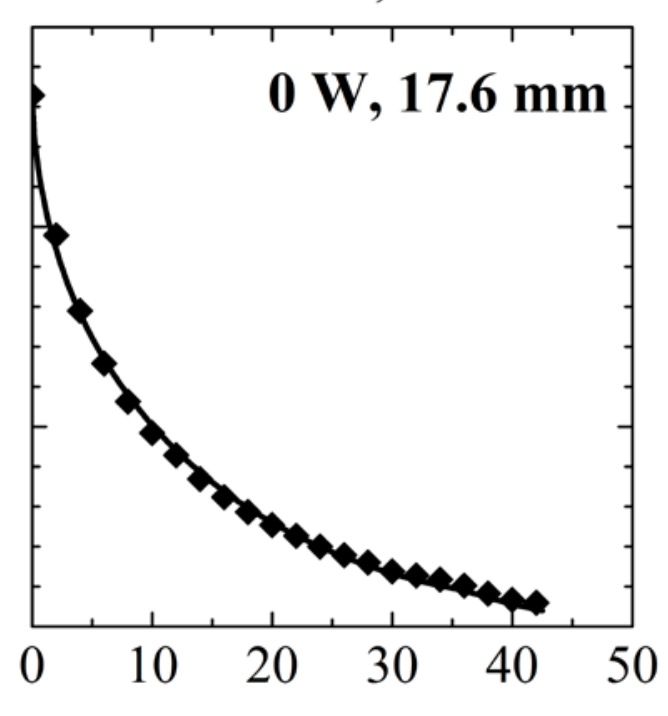

Time, h 


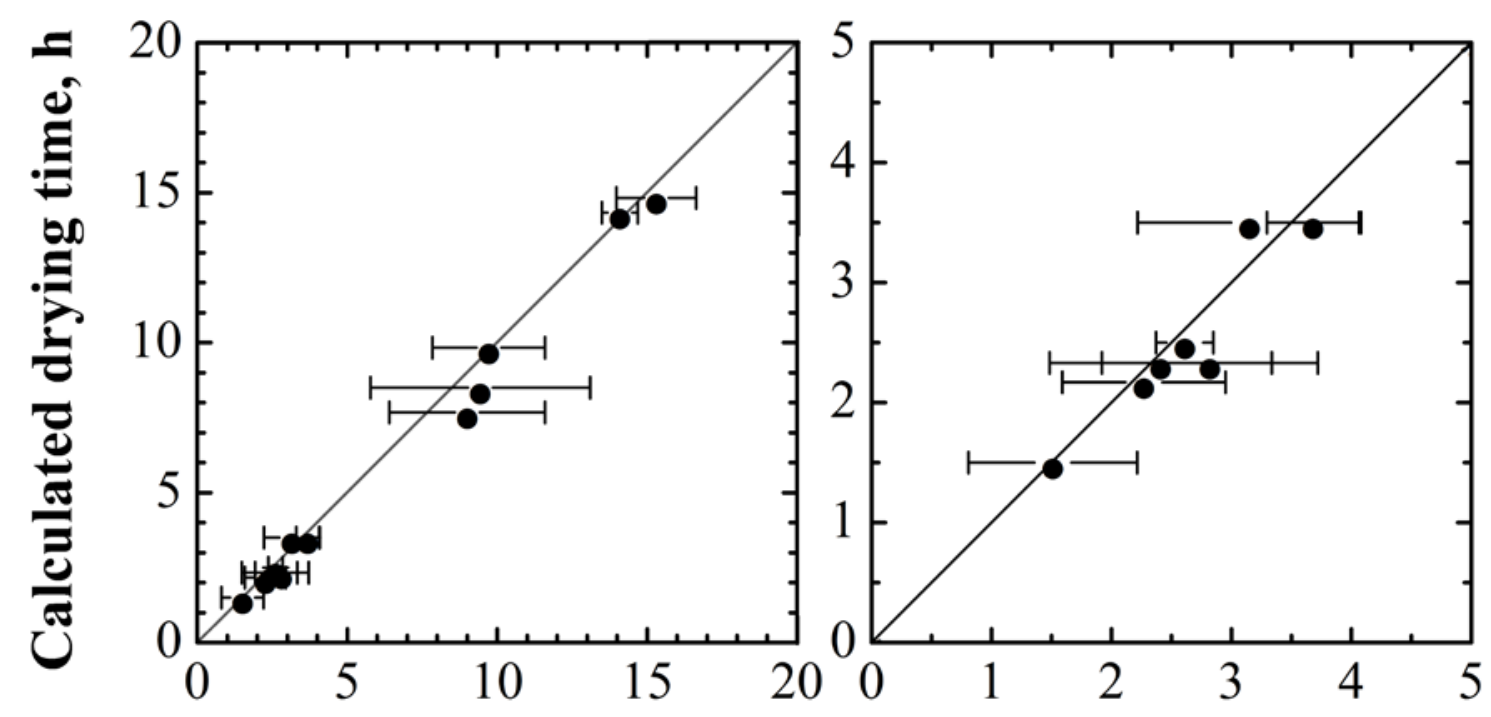

Measured drying time, $h \quad$ Measured drying time, $h$ 


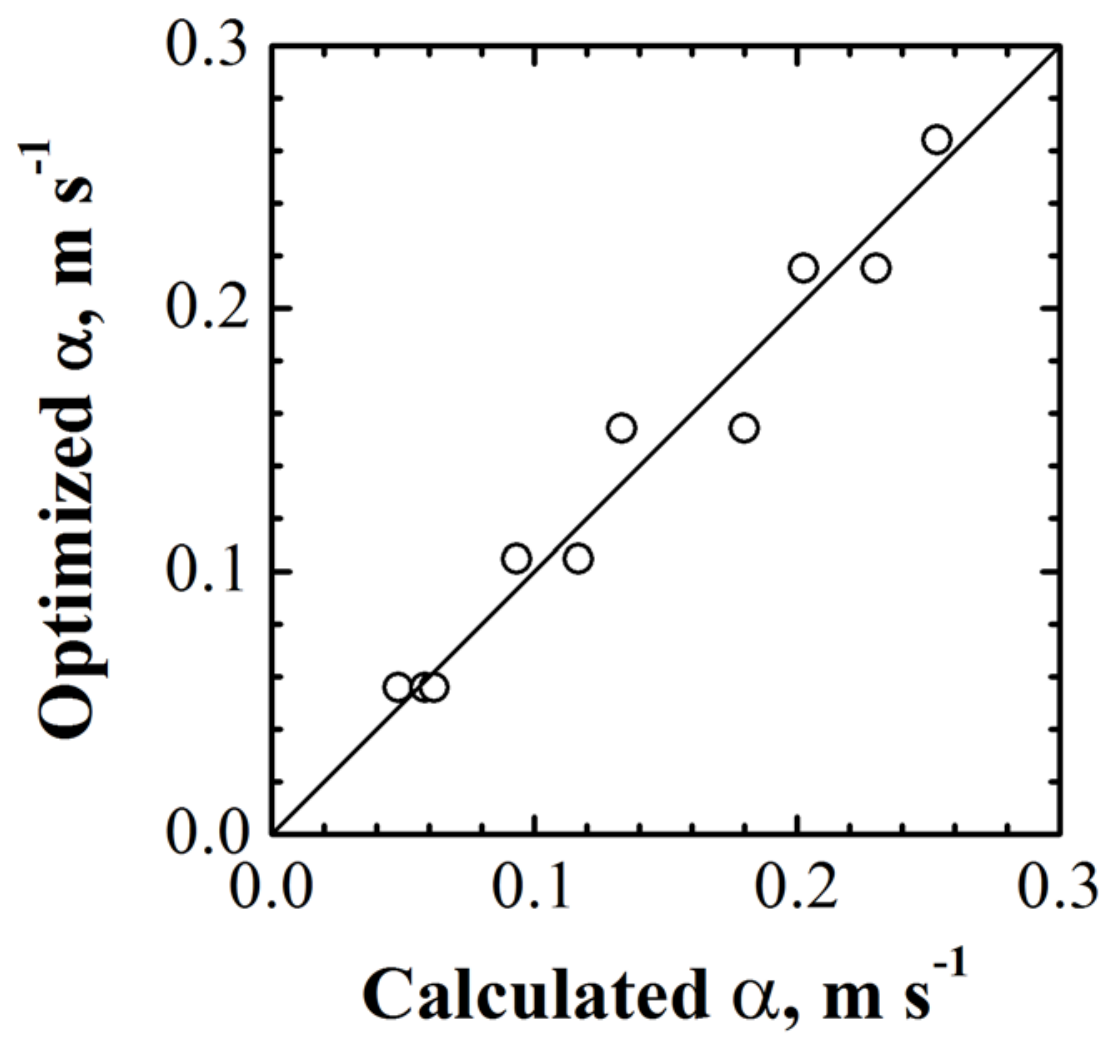



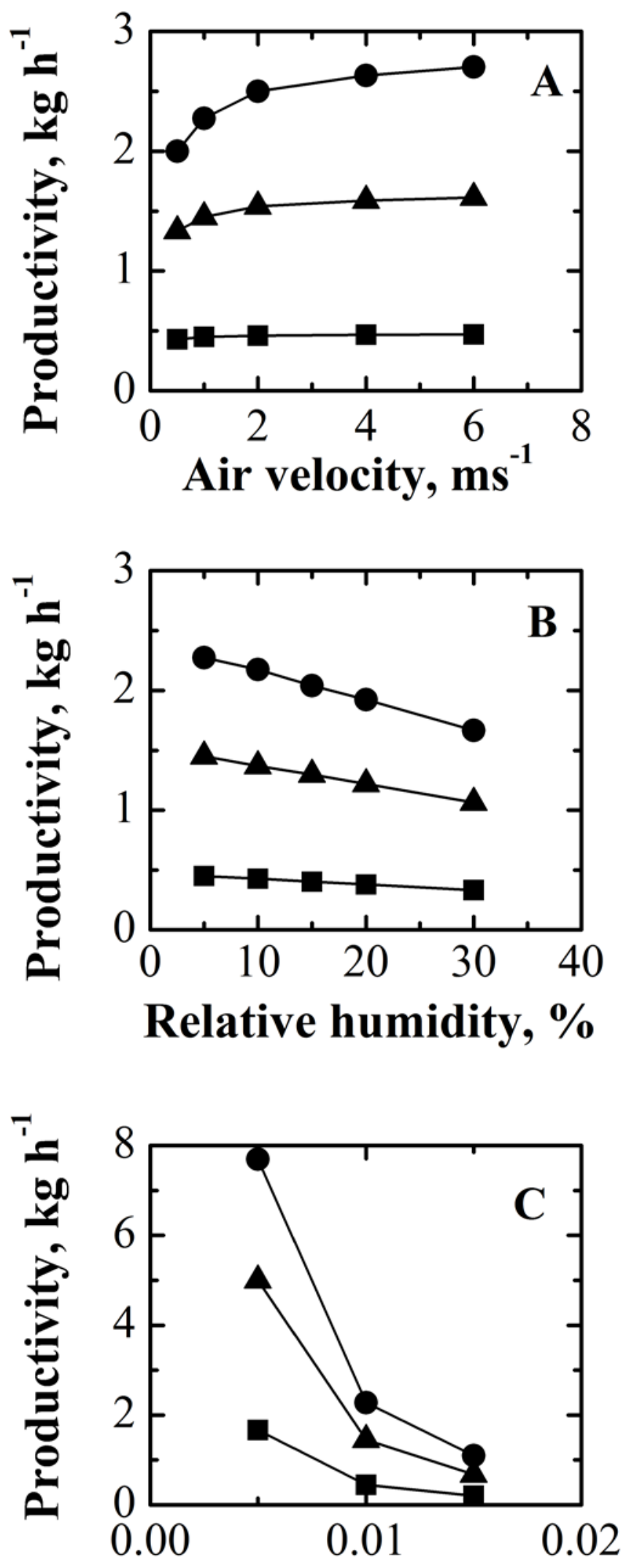

Thickness, $\mathrm{m}$ 

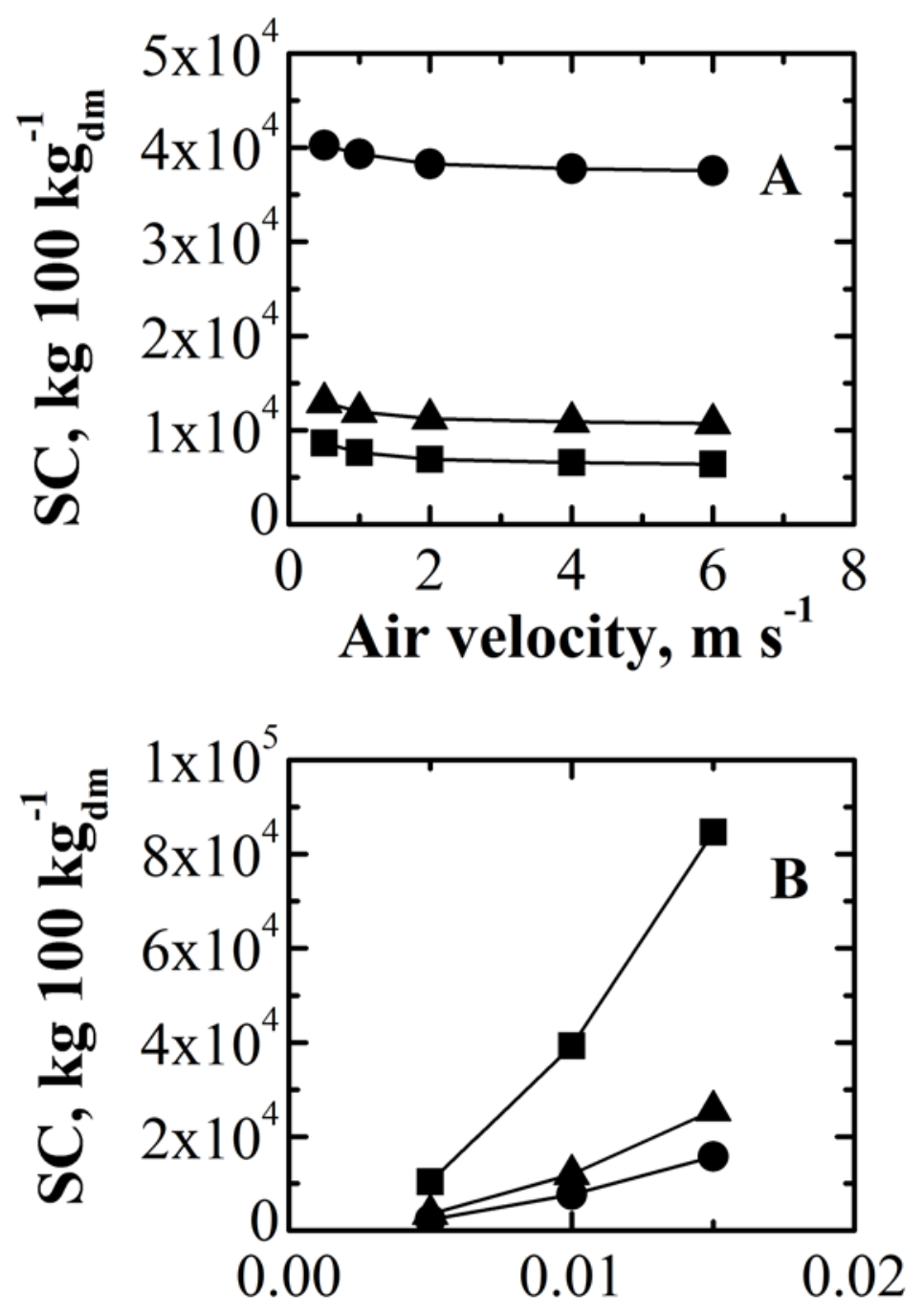

Thickness, $m$

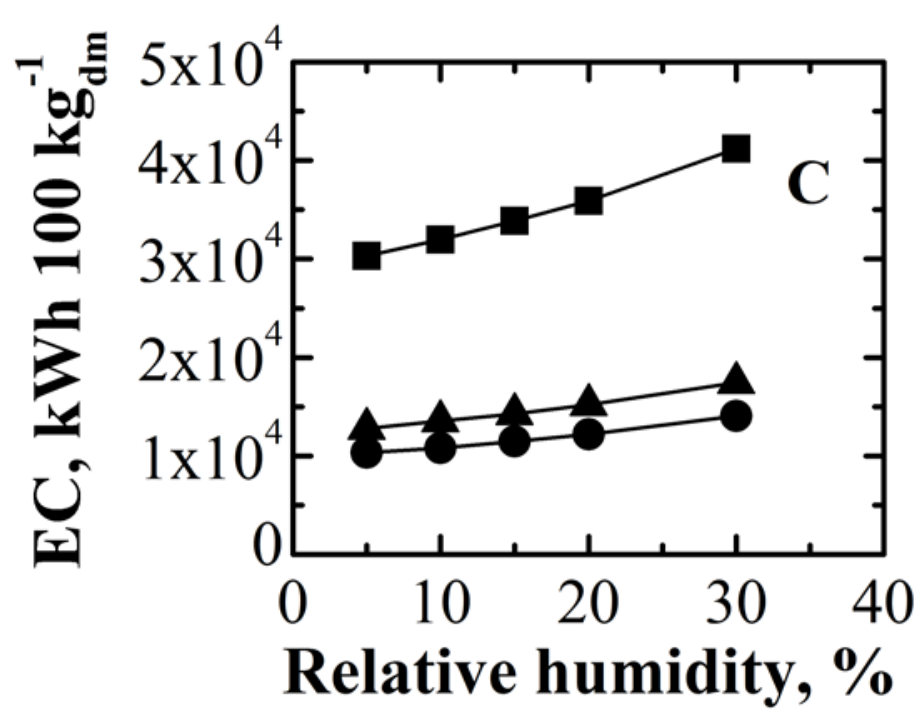

